O le Aso Ma le Filiga, O le Aso Mata'igatila

A qualitative study looking at Samoan language maintenance within second generation households

\title{
BY
}

Leitumalo Parsons

A thesis submitted to the Victoria University of Wellington in fulfilment of the requirements for the degree of Master of Applied Linguistics

Victoria University

2020 


$$
\text { O le Aso Ma le Filiga, O le Aso Mata'igatila }
$$

A qualitative study looking at Samoan language maintenance within second generation households 


\begin{abstract}
Samoan language within Aotearoa New Zealand has been labelled as "at risk" of becoming an endangered language if language shift continues (Hunkin, 2012; Wilson, 2017).

Language shift or language loss is defined as when a speech community gradually stops using one of its two languages in favour of the other, in this case English (Ravindrantha, 2009). The Samoan population is the largest community of the Pacific diaspora living in Aotearoa New Zealand. However, the use and maintenance of the Samoan language is rapidly declining. Although community-led initiatives have led to establishing of Aoga 'Amata (Samoan language and culture immersion preschool), Pacific Islands Early Childhood Association (PIECA) and the establishing of Samoan Studies departments within tertiary institutions, there continues to be an urgent need for government support and the implementation of Pacific language policies to ensure the continued use and protection of Samoan and other Pacific languages within the realm of Aotearoa New Zealand.

The three research questions framing this investigation are as follows:
\end{abstract}

1. How do the second and third generation Samoans view language and culture as contributing to their identity?

2. Where are second and third generation Samoans using and learning Samoan?

3. Is there a relationship between wellbeing and language shift?

O le Filiga Afa, a qualitative research methodology, was born out of this research in response to the need for a culturally responsive framework. Data was gathered through focus group and one-to-one discussions and included New Zealand - born Samoan speaking and non-Samoan - speaking Samoan participants. Key findings from this study include:

- All participants had a deep yearning for maintaining and revitalising their heritage languages;

- Language, culture and identity are intertwined and cannot be separated from one another;

- The role of elders, genealogy and the connection to culture contributes significantly towards the reinforcing and the maintenance of the Samoan language.

- A strong connection can be found between language shift and one's wellbeing. 


\section{Contents page}

1. Chapter 1. Introduction

1.1. My place within the research

1.2. Current point in time

1.3. Research Gap

1.4. Introduction of research

1.5. Research process

2. Chapter 2. Literature Review

2.1. Historical relationship between Samoa and Aotearoa

2.2. Language shift

2.3. Intergenerational transmission

2.4. Language policy

2.5. Case Studies

2.6. Aoga 'āmata / Language learning nests

2.7. Identity

3. Chapter 3. Method

3.1. Introducing Talanoa

3.1.1. Talanoa as a research method

3.1.2. Example of Talanoa in public communications

3.1.3. A problematic use of Talanoa

3.1.4. Talanoa and current research

3.1.5. Key finding of the research process

3.2. Research design

3.2.1. Introduction of $\mathrm{O}$ le Filiga le Afa

3.2.1.1. Purposeful nature of O le Filiga le Afa

3.2.1.2. Collective accountability

3.2.1.3. The then is the now and the now is the then

3.2.1.4. Spirituality of the process

3.2.1.5. Lima lelei

3.2.1.6. Space and place of $O$ le Filiga le Afa

3.2.1.7. O le Filiga le Afa as a Samoan research approach

3.2.1.8. Toli le niu

3.2.1.9. Husking of the niu 
3.2.1.10. Taomaga- Soaking of the husks

3.2.1.11. Sasa le pulu - Data collection

3.2.1.12. Faata'a - Thematic analysis

3.2.1.13. Filiga le Afa - Findings and Discussion

3.2.1.14. Wrapping of the Afa-Recommendations

3.2.2. Narrative inquiry

3.2.3. Researcher reflexivity

3.2.4. Data collection

3.2.5. Participants

3.2.5.1. Participants table

3.2.5.2. Focus group

3.2.5.3. Creating a space of comfort

3.2.5.4. Sasa le Pulu - Data collection

3.2.5.5. Participant feedback

3.2.5.6. One-on-one semi structured interviews

3.2.5.7. Research Questions

3.2.5.8. Matofi / Faata'a Data analysis

\section{Chapter 4 Findings}

4.1. Language, identity and culture are intrinsically interwoven. Lack of value placed on Samoan language within the educational system contributes to the shift of Samoan language

4.1.1. Little opportunity is available for Samoan language learning

4.1.1.1. Lack of continual bilingual educational support

4.1.1.2. Significance of Polynesian Club

4.1.2. Samoan News outlets, Music and News Papers

4.2. Role of genealogy, heritage, family and Samoan language maintenance

4.2.1. Samoan only speaking households

4.2.1.1. Significant role of Grandparents

4.2.1.2. Relationship between loss of Grandparents and feelings of disconnection

4.2.1.3. Sibling order

4.2.1.4. Role of Samoan Churches

4.3. O le alofa ma le puipui - Love and protection

4.3.1. First act of love - first generation migration 
4.3.1.1. Second act of love -fractures of relationships

4.3.1.2. Third act of love - new defining

4.4. Relationship between wellbeing and language maintenance / shift

4.4.1. Samoan language is spiritual and relational

4.4.2. A state of two minds

4.4.2.1. Presence of language promotes knowing one's place

4.4.2.2. Impact of being ridiculed for not knowing Samoan

4.4.3. Presence of Samoan language

4.4.4. Importance of participation

4.4.5. Impact of being ridiculed

4.4.6. Role of humour - connection to culture and a form of resilience

\section{Chapter 5. Discussion}

5.1. Discussion outline

5.1.1. Polynesian club

5.2. Role of family

5.2.1.1. Grandparents

5.2.1.2. Family support

5.2.1.3. Sense of belonging language provides

5.2.2. Churches

5.3. O le Alofa

5.3.1. First act of love

5.3.2. Fractures of relationships

5.3.3. Re-defining a better life

5.4. Wellbeing

5.4.1. Four core relationships

\section{Chapter 6. Conclusion}

6.1. Implications

6.1.1. Choice of methodology

6.1.1.1. Defining a new research process

6.1.1.2. Insider status

6.1.1.3. Gender imbalance

6.2. Recommendations

6.2.1. Policy development

6.2.2. Education policies 
6.2.3. Transition to school first language policy

6.2.4. Housing

6.2.5. Churches

6.2.6. Families

6.3. Concluding statement

7. Chapter 7. Final word 


\section{Acknowledgements}

Muamua ona si'i le fa'afetai I le Atua.

Thank you for getting me through this journey.

Thank you for surrounding me with a supportive, loving, caring village.

Thank you for giving me this opportunity and for all the blessings that I have received as a result of this thesis journey. Thank you for the learnings and growth.

Fa'afetai tele lava.

There are many people I owe great gratitude and thanks to for getting me to this point of completion, and surrounding me with support, love and strength. Although there are too many to name, a certain few must be acknowledged.

I must acknowledge Tuiatua Tupua Tamasese and Masiofo Filifilia Tamasese, for all the hard work that has gone into ensuring our language, culture, customs and traditions are not forgotten but preserved. Thank you for sharing your wisdom with such depth and meaning each time I read your works or listen to you speak I am moved with deep pride for our people, culture and rich history.

To my wonderful mother, fa'afetai tele lava for your unconditional support and love. For all your sacrifices you made to ensure I was well supported throughout my studies. Thank you for teaching me what resilience looks like and encouraging me every step of the way throughout this journey. I hit the jackpot when I was blessed to be your daughter.

To my aunt Taimalieutu Kiwi, thank you for the never-ending life lessons, guidance, conversations. Thank you for teaching me what research should be about. Thank you for all the clarity you brought during some of my most confusing times of trying to navigate western academia. Thank you for your guidance throughout the creating of the Filiga le Afa methodology and always having time to answer my questions - helping me to unclutter the clutter one conversation at a time.

Aunty Tafaoimalo Loudeen, thank you for working so hard to ensure myself and my cousins will always have a home in Samoa. Thank you for keeping Samoa alive for me, and for reminding me of my place in this world. Thank you for the guidance, encouragement, the soul food and constant love.

To my uncle Ifopo, thank you for taking the time to sit down with me and explain how 'afa is made. Thank you for your stories, knowledge and wisdom. Thank you for being so encouraging and sharing your stories of childhood with me. I would not have been able to have created the Filiga le Afa methodology without your wisdom and guidance. Fa'afetai tele lava.

To my aunty Sita and uncle Pesi, malo 'aupito for the constant prayers, support, love and encouragement. Thank you for the delicious baking and cooking and late-night conversations about what Talanoa means to us. I will always be grateful for your love and support.

Malo 'aupito to my cousins Danny and Jabez for all the prayers and love. 
Thank you to all my family who would constantly send words of encouragement and prayers. My aunts and uncles fa'afetai tele lava.

Thank you to my supervisor Corinne Seals, for trusting and backing me that I would complete this thesis. Fa'afetai tele lava for all your guidance and constant reassurance I was on the right path.

The biggest fa'afetai tele lava to the participants who agreed to be a part of this study. Without you, this research would not have been possible. Thank you for trusting me, thank you for opening up and sharing your stories with me. You went above and beyond, and I am so grateful to you. I hope this work represents your stories well.

Jenny Taotua, Victoria University's Senior Pasifika transition advisor. The only person who listened when we asked for help and acted immediately. Thank you for always having the right answers for me when I would come to your office in tears. Thank you for listening to me, and always being there for not just myself but all Pasifika students who get the privilege of gracing your office and receiving your love and support.

To the post-graduate Pasifika writing group, initiated by Jenny Taotua. It was an absolute honour to work alongside you on Saturday mornings and listen to your stories of resilience. Fa'afetai tele lava. I always left our writing sessions feeling inspired and motivated.

Thank you to my incredible best friends, Victoria, Vi'i, and Shara-Lee thank you for always understanding when I would miss a catch up, birthday or dinner. Thank you or always sending me loving messages of support and letting me vent to you about my frustrations and challenges. Thank you for always being there for me and thank you for your loving sisterhood and friendships.

To my bestie Hamish, thank you for always checking in, for all the food drops to uni, keeping me company during my late nights of writing and for always entertaining my ridiculous procrastination conversations. I will always be grateful for your support and friendship.

Fakafetai lahi lele to my fellow Tuakana Ateli. Thank you for always making me laugh during some of the most stressful times. Thank you for being the best hype person, for always listening to my rants and for your generous supporting loving friendship throughout my thesis journey.

Special mention to Jessica Poasa, thank you for being my walking Samoan dictionary and translator. Thank you for the vent sessions, support, friendship and love.

Vinaka, Vinaka vaka levu to my dear friend Luka. Thank you for being my bouncing board for ideas, thank you for looking over my work with a fresh set of eyes and for the amazing helpful suggestions. Thank you for always helping me and pushing me to do better. I am so grateful to you and your generous heart and brilliant mind.

Thank you to the Anglican Family Centre for providing a warm safe study space with free printing and parking.

To my work, thank you so much for the ongoing support, encouragement and giving me time off when needed with such little notice. Thank you especially to my team leaders Taitu and Sam for being so supportive and understanding. 
This thesis is dedicated to my mother, Lucy Lauluanofo Parsons.

I love you mum. 
O le Aso Ma le Filiga, O le Aso Mata'igatila

A qualitative study looking at Samoan language maintenance within second generation households 


\section{Chapter 1. Introduction}

\section{O le Aso ma le Filiga, O le Aso ma le Mata'igatila}

Each day brings its own views of what is on the horizon; each day brings its own choices.

My interpretation of this proverb is that I, we, must always be looking forward to the horizons to find new ways to move forward to keep our language alive and thriving. As each day brings its own choices, ancestors and present and future generations to come must inform my/our thinking and actions.

\subsection{My place within the research}

When I first heard this proverb and the meaning behind it, I felt it was a fitting title for this thesis. I hold language close to my heart. Although I wouldn't call myself fluent or competent in either of my heritage languages, feeling and knowing the impact of what it means to not be able to speak your mother tongue has strengthened my appreciation and love for my languages, inspiring me to look at new ways of reclaiming and reconnecting to my language and culture.

I am a young Samoan Tongan woman. My mother hails from the villages of Falealili in Upolu, Sapapalili'i in Savai'i and Papauta in Upolu, Samoa. My father hails from Nukualofa, Tonga. Born and raised in Aotearoa New Zealand, I am considered second-generation Samoan. Second generation being termed as someone with one or both parents born outside of Aotearoa (Second generation New Zealander, n.d).

My maternal grandparents migrated from Samoa to Aotearoa New Zealand for educational and employment opportunities. My paternal grandparents migrated from Tonga for the same reasons. My maternal grandparents were advised by my mother's primary school teachers to speak only English in the home as this would be the best way to support their children's educational success. So, what was once a Samoan speaking household, switched to becoming a bi-lingual but predominantly English-speaking household. This resulted in a Samoan language shift occurring within the space of one generation. Holmes (1993) noted that complete language shift could occur over the space of four generations, 
however other case studies have indicated it could be completed within as little as two generations (Wee, 1974; Stoffel, 1982 cited in Holmes,1993).

Although I was not raised being able to speak Samoan, my elders and family made sure I was raised and immersed in Samoan culture and values. In an attempt to reclaim my ancestral languages, I have sought different pathways of learning the Samoan language. This has included participating in courses at school and university. With each learning opportunity my desire to find the most meaningful and practical way of learning increased.

\subsection{Current point in time}

Over time Aotearoa has grown to become one of a small number of culturally and linguistically diverse countries (Spoonly \& Bedford, 2012). Contributing to this diversity is the ever-growing Pacific population, which is the fourth largest major ethnic group in Aotearoa to follow European (StatisticsNZ, 2013). My inability to speak my heritage language is a familiar and an increasing phenomenon throughout Aotearoa.

McCreanor (2019) notes that over ninety percent of Samoans living in Aotearoa speak English.

In looking at census data between 1996, 2006 and 2013, for New Zealand - born Pacific people (identified in seven ethnic groupings), a steady and consistent heritage language regression was evident (p32). Wilson (2017) talks about the Samoan language eventually moving into a category of being deemed "endangered" if preventative steps are not taken immediately.

This ongoing regression of heritage languages is a sign of serious concern, signalling an immediate need for action to ensure the survival of heritage languages within Aotearoa (McCaffery \& McCaffery, 2010). 


\subsection{Research gap}

Knowing that the language is at risk of becoming an endangered language (Wilson, 2017), I decided to investigate case studies within Aotearoa New Zealand which looked at Pacific language retention. Four case studies prompted me to start my own research journey of looking at Samoan language maintenance. Authors Holmes et.al, (1993); Davis \& Starks, (2005); Sauvao, (2002) and Starks, (2005), noted four significant factors which contributed to language maintenance. These factors were:

* church involvement;

* strong family relationships;

* continual bilingual educational support; and

* the important role language has regarding identity, and how this contributes to the maintenance of a heritage language.

I also wanted to look at the Samoan diaspora within Te Whanganui -a-Tara Wellington. I wanted to examine if my own experiences were shared by other Samoans, and I also wanted to understand if these maintenance factors were still relevant today, or relevant to a Samoan second generation living in a city with a low Samoan population.

According to Statistics NZ (2001), the population of Samoans living in Whanganui-a-Tara was recorded as $17 \%$, compared to $66 \%$ of Samoans living in Tāmaki Makaurau Auckland. I wanted to find out if my own research findings would differ to a study that was conducted in Tāmaki Makaurau (Statistics NZ, 2001).

In Wilson's (2017) research, a key theme and belief was identified among young Samoans, who believed that "If you do not use your language then you do not value it". I value my language immensely, but I wasn't afforded the same opportunities to maintain it. 


\subsection{Introduction of research}

The purpose of this research is to answer the following questions.

1. How do Samoan second generation see language contributing to identity?

2. Where are second generation Samoans using and learning Samoan?

3. Is there a relationship between wellbeing and language shift or/ maintenance?

These questions, along with my own experiences inspired me to take on this research journey.

The three questions helped me clarify and understand whether the Samoan language is declining at a fast rate (McCreanor, 2019). Previous studies have indicated that language and identity are connected (Nieto, 2002) and this raises the questions of how second generation are shaping and negotiating their identity today. Tiatia (1998) expresses that authentic Samoan identity necessitates linguistic comprehension and ability. (Exploring what identity means for the participants is included within this work.)

By learning where second generation Samoans are using and learning the Samoan language - is to understand whether the factors once believed to play a crucial role in heritage language retention (Anahina'aipolo, 1993; Davis \& Starks, 2005; Sauvao, 2002; Starks, 2005) are still valid and what new ways or initiatives do we need to look at to help us in preventing the further decline of Samoan use.

The third question is aimed at understanding how the shift or presence of a heritage language can impact one's wellbeing in order to gain a better picture of what this will mean for the future of both the peoples and culture of Samoa within Aotearoa.

\subsection{Research process}

As I started my journey of research the process pointed me toward the developing of a culturally derived Samoan research method "O le Filiga le Afa". Guided by family elders, Samoan cultural experts and community leaders, this qualitative method has a narrativefocused approach. Data was collected through semi-structured interviews and a thematic analysis carried out. 
As second-generation Samoan and Tongan, I have a direct connection with the research context having 'insider status' (Given, 2008). It was through personal networks and connections that participants were approached and agreed to participate.

Three key findings of this relate to language, identity and culture. Their interconnectedness and the impacts of language shift on mental, physical and spiritual wellbeing are evident within this work. Acts of love and protection, of wanting to promote educational and social success for second generation Samoans have and continue to be complex and can also be seen within this work. 


\section{Chapter 2 Literature Review}

\subsection{Historical relationship between Samoa and Aotearoa}

Samoa and Aotearoa New Zealand share a unique relationship dating far back to the early 1900's. A brief summary of events that occurred during New Zealand administration of Samoa during the 1900's provides a glimpse into the complex and historical relationship between Samoa and Aotearoa.

In 1914, New Zealand troops arrived in Samoa to take over the administration of Samoa from Germany under the leadership of Colonel Robert Logan. World War one was currently taking place and New Zealand was said to be wary of an enemy power so close to New Zealand shores (Kerslak, 2010). New Zealand imposed a military takeover which then declared the taking of Samoa as the first allied victory of the first world war (Field, 1991).

\section{$\underline{\text { Influenza epidemic }}$}

In 1918, while under the leadership of Colonel Robert Logan, the Spanish influenza reached the shores of Samoa by the ship Talune. Whilst New Zealand was very much aware of the Influenza epidemic at the time, no action was taken to caution or inform Samoa of the current epidemic, and passengers aboard the Talune were infected. The Auckland port bill of health for the Talune made no effort to mention this to authorities upon arriving at Apia (Field,1991).

The Talune brought the influenza epidemic which killed $25 \%-33 \%$ of Samoa's total population (Field, 1991). It was reported the eldest generation, young men and children were the biggest victims of the influenza epidemic. The sudden loss of young men also meant families suffered even further from starvation as there was no one to fish, collect, prepare, and cook the food all laborious tasks. Salesa, (2017) raises the point that such devastation also meant that a generation of leaders and carers were lost.

The destruction of epidemic in the opening up a gap in oral history, traditions and customs caused several generations were to be lost. A major impact of this is reflected in Samoa's Titles, Lands and Customs court, as there is a heavy reliance on German Anthropologist Augustine Kramer's (1995) book which documented his interpretation and perception of the chiefly system of each village (Field, 2017). 
In 1921 the Western Samoa Act was created and introduced, making Western Samoa a part of New Zealand territory. This act meant that the New Zealand government would have full power of the administration and legislation over Samoa (Kerslake, 2010) an Act not welcomed by many of Samoa's leaders at the time (2010).

\section{$\underline{\text { The Mau }}$}

Following on from this, the rebirth of the Mau movement came to light. The Mau advocated for "Samoa mo Samoa" self-government of Samoa by Samoa. The Mau organisation held ninety percent support from the Samoan people and addressed social, civil, and political issues in Samoa (Field,2006). Pacifism, non-violence, and commitment to democratic change was the grounding manifesto of the Mau movement (Field,1984).

It was a movement that actively challenged New Zealand administrators, a voice for the Samoan people expressing grievances on behalf of Samoa. Non-violent well organised protests by the Mau was becoming increasingly difficult to be ignored by New Zealand administrators (Kerslak, 2010).

\section{Black Saturday}

On December 28, 1929, a peaceful procession led by the Mau turned into a scuffle with the New Zealand police when attempting to arrest a member of the Mau resulting in police opening fire on the non-violent passive protest, killing nine people and wounding fifty more. It was not until the police had halted firing on the peaceful marchers that they realised they were not and had never been under attack (Field, 1991). Of the nine dead Tupua Tamasese Lealofi III was shot and killed. What made Tupua Tamasese Lealofi III death more heart breakingly significant was his call for passive resistance and peace during his final moments. Tamasese Lealofi III was said to have turned to the crowd when police opened fire, shouting in both English and Samoan "filemu Samoa" peace Samoa" urging the Mau marchers to not panic and stay calm. As he lay dying Tupua Tamasese Lealofi III used his last breath to reiterate the importance of passive resistant "My blood has been spoilt for Samoa. I am proud to give it. Do not dream of avenging it, as it was spilt in maintaining peace. If I die, peace must be maintained at any price." This day became a significant and historical day for Samoa, which would be known as Black Saturday (Field, 2006). 


\section{$\underline{\text { Independence of Samoa }}$}

After years of passive resistance, petitions, submissions to the constitutional convention and League of Nations requesting independence and self-sovereignty (Meleisa, 1987) Samoa finally gained independence in 1962. A "Treaty of Friendship" was created and signed between Samoa and New Zealand (Meleisa, 1987) An acknowledgement of the special relationship between Samoa and New Zealand (Kerslak, 2010) despite the gross injustices committed against Samoa by the New Zealand administration.

\section{Migration}

In the 1950s to the 1970s New Zealand underwent an economic boom. The need for unskilled labourers to fill manual tasks in factories, roading, forestry and construction led to the relaxing of immigration laws for Samoan and other Pacific communities. The 1960's were known to be the industrialisation period and by 1966 the number of Samoans living in Aotearoa were 11,842 and only continued to grow (New Zealand Population Official census 1874-1966 found in Kerslak, 2010).

The high influx of Samoan workers and labourers was much needed relief to the New Zealand workforce and economy (Kerslak, 2010) until the 1970's when the National Party tightened its immigration laws which led to the Police to 'flush out" Western Samoan over stayers (Samoa Times, Feb 4, 1977). The act of "flushing out" would later become known as the Dawn Raids. Once over stayers were identified, immediate removal and deportation to Samoa follow (Kerslak, 2010).

Although there were several Pacific Island nations and communities impacted by the Dawn raids, Samoans were the primary target (Kerslak, 2010). In a study carried out in 1985-86 Pacific Island people comprised only a third of over stayers, but yet they made up $86 \%$ of all prosecutions for overstaying. Citizens from the United States and the United Kingdom made up almost a third of those overstaying but, represented only $5 \%$ of prosecutions (2010).

Ironically, article one of the Treaty of Friendship states that the relationship between New Zealand and Samoa should be governed by a close friendship that ensures good future relations. In less than ten years of the treaty being signed and Samoa gaining independence it would seem New Zealand had forgotten both the treaty and its 
commitment to Samoa to be mindful of the past relationship and events that had occurred under the New Zealand administration.

\section{Moving forward}

In 2002, Samoa celebrated its fortieth-year anniversary of Independence. Helen Clarke, the then Prime Minister for Aotearoa New Zealand attended Samoa's independence celebrations in Samoa. Helen Clarke took this time to publicly acknowledge and apologise for New Zealand's colonisation of Samoa and its resultant atrocities (Kerslak, 2010).

Understanding the historical relationship between New Zealand and Samoa identifies the role New Zealand has played in regard to the changing of the Samoan landscape, linguistically, culturally, and historically. Bringing forth the question of what Aotearoa New Zealand can do now, to help slow or prevent the shift of Samoan language.

\subsection{Language shift}

Ravindrantha (2009), defined language loss as the process in which a speech community gradually stops using one of its two languages in favour for the other. Considering the significant drop in Samoan speakers in Aotearoa New Zealand and the increasing literature and case studies published recently including Saovao-Vau'li (2017); Wilson ( 2017); King \& Cunningham (2017); Hunkin (2012); Savao (2002); Masina (1996); Starks(2005); Holmes(1993); Tiatia (1998) and Anae (1998), the common theme reveals that the Samoan language is shifting and Samoans living in Aotearoa could be faced with Samoan language loss in the next few years.

\section{Health of a language}

By 2050 , it is assumed that half of the world's 6,000 or more languages will be dead, with languages becoming extinct at twice the speed of endangered mammals and four times the rate of endangered birds (Ostler, 1999).

A healthy language is regarded as a language that acquires new speakers, no matter how many adults use the language if it is not passed on to the next generation it is assumed that its fate is sealed (Ostler, 1999). 
Globally indigenous and tribal languages have suffered significant language loss and shift. Australia as an example, Indigenous languages exceeded 250 languages, 150 are now extinct and 70 are endangered. Papua New Guinea had 850 Indigenous languages recorded, a third are now at risk of disappearing. Going beyond the Pacific, Celtic languages including Irish, Welsh, Scots Gaelic and Brenton are in danger despite the efforts of the recent government policies encouraging the languages revival (Ostler, 1999).

Both North and South Americas are reported to have suffered the worst language devastation during the eighteenth and nineteenth-century colonisation. Communities that live in large numbers away from their homeland are also most likely to face language shift or loss (Garcia,2003).

Over the last two decades Aotearoa has grown to become one of a small number of culturally and linguistically diverse countries (Spoonley \& Bedford 2012). Contributing to this diversity are the Pacific communities, which according to the 2013 New Zealand census, is the fourth-largest major ethnic group following European, Māori, and Asian ethnic groups. Samoan People remain the largest cultural group within Aotearoa New Zealand's Pacific community, sitting at nearly half of the total Pacific communities' population, 144,138 (Statistics New Zealand, 2013)

Although the Samoan community may be the largest of the Pasifika community in Aotearoa, there is a serious need and concern regarding the maintenance of the Samoan language. A majority of Aotearoa New Zealand's languages of the realm have been labelled as endangered (2019) although Samoan is not currently sitting on that list it is only a matter of time (McCreanor; 2019, Hunkin, 2013; Wilson, 2017). Ninety percent of Samoans living in Aotearoa New Zealand speak English, and sixty two percent of the Samoan population are Aotearoa born (Statistics New Zealand, 2014a). Immediate and urgent action is required to prevent the further regression of Ancestral languages (McCaffery \&McFall-McCaffery, 2010).

Te reo Māori Aotearoa, Te reo Māori o Rarotonga and the Rotuman languages have been listed as "vulnerable" (McCreanor. 2019), thus indicating the negligence of New Zealand and it's duty and care to ensure native languages thrive (p.32). 


\section{$\underline{2.3 \text { Intergenerational Transmission }}$}

Evidence shows a lack of intergenerational transmission, the transfer of individual abilities, traits, behaviours and outcomes from parents to children (Lochner, 2008) is occurring. Cunningham and King (2017) found that although Māori and Samoan have the largest numbers of children who speak their heritage language, they do not have the highest intergenerational transmission rate, other than English.

The Korean language has the highest transmission rate of $83 \%$, whilst the Samoan language is at $55 \%$ and te reo Māori is at $44 \%$. King and Cunningham went on to explain that $50.6 \%$ transmission occurs for Samoans born in Aotearoa, in comparison to $81.2 \%$ for Samoans born in Samoa and now living in Aotearoa.

Wilson found that children who lived in a household with two or more Samoan speaking adults had a higher chance of being able to speak Samoan (2017).

Lesa (2009) noted several reasons for the decrease in transmission rates. One reason being based on the idea that Samoan is not a language that is seen as successful or a language that can help their children in the establishing of themselves within a successful career. Although parents deemed the language important regarding one's connection to culture and heritage, English took precedence within the home and also in Church.

Church, a place that was once seen as the hub of Samoan language maintenance is becoming a place in which there is little opportunity to speak or practise Samoan for Church youth groups (Lesa, 2009; Wilson, 2017). Although Lesa's (2009) study was based in Hawai'i, Lesa's findings were similar to findings conducted in Aotearoa New Zealand by Wilson (2010, 2017).

This notion of Samoan not being a language that is as powerful or seen as successful falls in lines with the idea of linguistic imperialism. A term that is described by Phillipson (1997) as the structural circumstances which contributes to the loss of minority languages (Hunkin, 2013).It is easy to understand how one can come to think this of their own heritage language when recent arrivals to Aotearoa have had to assimilate and adopt to a new country, or where the first generation Samoans are raised in a country that is not their motherland. I think of my grandparents, my mother's parents, who migrated from Samoa to Aotearoa in the early 1950's and raising their children in Otara. My grandparents' adoption of English as the dominant language and adhering to mainstream social expectations, 
pressures and norms were viewed as being 'success'. Unfortunately, this resulted in first generation language shift, directly impacting, and leading to second generation language shift.

My family is not isolated in facing significant language shift, Galumalemana Alfred Hunkin (2013) points out how these exact "hegemonic influences" are a part of a colonial mind-set that convinces parents that the only way their children will succeed is through English.

Skutnabb-Kungas (2002, found in Hunkin, 2013) argued that when there is no other alternative but to use English in every domain other than your home life, it is merely impossible for English not to become a killer language. Hunkin (2013) talks about the assimilation policies, one in particular, that effectively expected Samoan parents to teach their children "broken English", and he discussed how detrimental this was for the learning of the children and in hindsight, had long lasting consequences because of this.

The supporting evidence towards language maintenance is only growing in regard to being able to speak two or more languages and is seen as having many advantages in all aspects of life. This is supported by Norton (2008); Toloa (2010); Wilson (2017); Hunkin (2012), Bell (2008); Tuafuti; (2016) and Toloa (2010).

Toloa (2010) argues that the importance of being able to speak Samoan is critical as it contributes significantly to one's education achievements, and pushes further to question what the academic achievements will look like in the future for Samoans should the language continue to shift.

\subsection{Language policy}

The lack in language policy in Aotearoa is also identified as another contributing factor for minority language loss in Aotearoa (Wilson 2017; Holme et al, 1999, Hunkin, 2013). A language policy project was prepared in 1991 within the Ministry of Education with the aim to produce a report for the development of a language policy for Aotearoa (Waite, 1992).

The project named Aoteareo Speaking for Ourselves (Waite, 1992) explored the high need for a coherent and comprehensive New Zealand languages policy as a grounding framework to inform decision making to address language issues confronting New Zealand society. Unfortunately, this language policy never came to fruition, however, it did highlight 
the beneficial and crucially important role it could play in regard to the maintenance of heritage languages in Aotearoa. The document also emphasised the great need for a language policy which worked towards maintaining ethnic languages, encourages the building of relationships between different communities in Aotearoa through the normalising and learning of minority languages, however, the focal point for the government in 1994 was to "reflect changes in New Zealand's international trading situation by including the languages and cultures of our Asian trading partners" (Benton, 1995).

The benefit of commercial languages to New Zealand was rooted in economic gain, stating this gained greater precedence than the retention of heritage languages.

\section{$2.5 \underline{\text { Case studies }}$}

Recent studies published in the last decade highlight different themes or factors contributing to the maintenance of Samoan language and the prevention of language shift. Wilson (2017) found that the responsibility of maintaining and learning the Samoan language sat with the families first. The pivotal role grandparents and elders can have in Samoan language maintenance within three generational households is significant.

Wilson acknowledges that English is found to be dominating Church groups such as Autalavou and A'oga Sā. This shift is surprising as Church's were once seen to be the stronghold for the sustainability of the Samoan language (2017). Wilson fears for the future of the Samoan language and urges that more sustainable approaches of understanding how language can be passed on and maintained needs to be a focal point (2017).

Saovao-Va'auli (2017) discusses for the need for more Aganuu classes on both language and culture starting from the basics of language teaching and learning. Sauvao-Va'auli explores how beneficial these classes were for him as an adult needing to connect back to his culture and language and having a more in depth understanding of the Samoan culture, traditions, and customs (2017).

The need for Aganuu classes aimed specifically for adults brings to light that although the responsibility of teaching, maintaining and learning the language falls within the family, there are no guarantees all Samoan adults have the knowledge, language cultural 
expertise to pass on to younger family members. Ensuring the language is maintained and is passed on.

Aganuu classes are a starting point for families wanting to forego the journey of learning and reconnecting to their culture and heritage. Sauvao-Va'auli findings demonstrated how beneficial these learning opportunities are and have been, in regard to growth in confidence, knowledge and well-being. As a participant in Aganuu classes, my own and my family members' experiences were carried out within a safe welcoming learning space which catered to older, young and future generations.

Both Dickie \& MacDonald (2011) and Fouvea (2013) explore the way in which Churches contribute to the maintenance of Samoan language and increase reading literacy. Fouvea (2013) reiterates that in order for the language to be maintained, sufficient support at both home and Church must be provided. Through exploring the role and core properties of fono, Fouvea (2013) found that Samoan language is provided via socialisation through the properties of relationships and identity.

Fouvea (2013) concluded that the properties of fono would be "key vehicles" for Samoan people to use that would contribute to the maintenance of Samoan language. Whereas Dickie and MacDonald (2011) provide examples of Samoan language maintenance through Sunday school, Sunday school examinations and taulotu in which children are given a bible verse to learn, memorise and repeat back to the Church congregation. MacDonald \& Dickie (2011) explore the role of ā'oga 'āmata (preschool), Church involvement, and they identified Church as a source for being maintenance of both language and culture.

Holmes et al (1993) in observing the maintenance of three community languages: Tongan, Greek and Mandarin, in Wellington, supports the notion that Church can be a large contributor towards community language maintenance.

Although Church may be a driving force for the maintenance of Samoan language it cannot be guaranteed that Church is as popular as it used to once be for Samoan families and for the new Samoan generations. Lesa (2009) points out that many ministers, in an attempt to keep the young people in Church, are now using English throughout their services, and adults only use Samoan when talking to one another but switch to English when speaking to the youth or young people of the Church. 


\section{6 Á'oga 'āmata and Language Nests}

Bilingual education and Samoan language emersion centres such as ā'oga 'āmata otherwise known as preschool and early childhood language nests, were set up as a community and Church response to the need for bilingual and Samoan emersion centres to ensure the maintenance of Samoan language and culture in Aotearoa (Ete, 1993).

King \& Cunningham (2017) found that in 2012, 473 ECE Samoan immersion centres were established. However, 283 of these were at the lowest level of immersion (1-11\%). A clear indicator that there is a lot of work needed regarding providing improved funding, resources and trained Samoan-language teachers in Samoan immersion language services.

Savao (2002) investigated the transition strategies from Ā'oga 'āmata to primary school and revealed that many positive and effective transitional strategies were implemented to help children's transition from ā'oga 'āmata, however, the support for children's Samoan language use and growth was heavily reliant on the children's families.

Primary schools were lacking in providing an adequate support system, and children who transitioned into primary schools with no transition to school support took a longer time to adjust. Children would lose the Samoan language they had learned at the Ā'oga 'āmata (Sauvao, 2002). Tuafuti, (2016) who met and talked with parents and families directly involved in the establishing of Aoga 'âmata or Samoan bilingual units in Auckland, found that although parents were very supportive and would drive their children from one side of the city to the other to ensure they could attend a Samoan bilingual unit, were not properly consulted when schools set up bilingual units. However, funding support and -a heavy reliance was put on the parents and communities (Tuafuti, 2016). Samoan parents who had advocated for Samoan bilingual units at their children schools were not considered as key stakeholders or given opportunities to be involved in discussions and decision-making. and decision making.

Although intentions by schools seem to be true and good, seeking adequate funding and government support, and full consultation and participation in each process would have reflected a more considered and respectful approach towards Samoan parents and families. Consultation with parents and family's needs to go beyond only fundraising, but also at each stage, as they are key stakeholders in their children's education and language maintenance. 


\subsection{Identity}

"Nā te reo te kākahu o te whakairo, te heuarahi kit e āo turoa o te hinengaro. Ko te reo, te mauri o te mana Māori.

Language clothes one's thoughts, one's ideas, and provides the pathway to enlightenment of the mind. The Mãori language is the ethos that embodies all that is to be Māori (Sir James Henare).

Language and identity are connected (Neito, 2002), signalling one's place of belonging, ways of knowing and ways of acting, and the beliefs, ideas and practices specific to a cultural group. It is, in a sense, a vehicle for culture and the maintenance of that culture.

The struggle of identity, being raised and living in Aotearoa as a Pacific person, is not unfamiliar. Many past works, literature, poems and thesis have been based on such experiences, and writers including Albert Wendt, Karlo Mila and Selina Tusitala Marsh discuss identity or themes of identity within their own work.

In 2013, Wilson's thesis looked at Pacific and Aotearoa literature exploring what it might mean to be a Pasifika person today. The attempt to understand identity or expression of identity, through the use of Pacific and New Zealand literature signals that ever-evolving ideas that may be surround the notion of identity.

To delve deeper into understanding identity for Samoans or Pasifika in Aotearoa, one needs to also have a better understanding of the complexities that sometimes come with being Samoan in Aotearoa. To understand these worlds better Risati Ete (2004) a young Samoan and rising theologian, discusses his ideas on what he believes is at the heart of the identity crisis, when contributing to Clive Pearson's Faith in a Hyphen: Cross-cultural theologies down under (2004). Ete brings forth the notion of being successful in both social entities can result in the destruction of the other. Highlighting the constant struggle of communalism and individualism, the back and forth between the unquestioned obedience and faaloalo versus critique and speaking out (2004).

Ete, (2004) talks of being Samoan in Aotearoa as never being able to truly find ones place of belonging because of the constant struggle over fa'a Samoa versus the palagi way, and speaking English or speaking Samoan, family and church obligations versus work and education obligations. 
Ete leans on the concept that neither cultures embrace "us" unconditionally. (Tamasese, 2009), whereas Unasa in his chapter 'The Borderlands: Relocating Samoan identity" in Su'e Su'e Manogi, (Tamasese, 2009) looks at how such constant internal negotiation has come to be and the "shaping of the New Zealand Samoan identity" (p. 357).

Unasa (2009) raises the point that proficiency in English language is what paved the way for a more prosperous and successful future for their children and future family generations. The concept of faaniusila vs FaaSamoa came about when the first Samoan migrants arrived into Aotearoa. Trying to hold onto their own ways of life and traditional customs whilst also welcoming the daily realities, adapting, and at times, substituting FaaSamoa village practices for the practical and convenient New Zealand life (p357).

Tiatia (1998), in talking with young Samoan, Tongan and Niuean youth about Pacific New Zealand born perspectives and the role the church plays in their lives, discusses identity and how being able to speak ones heritage language comes into play in regard to how one sees themselves in Aotearoa.

Stating that to speak Samoan competently alludes to the idea you are a true Samoan. Tiatia touches on language and the connection to language and identity. This notion of being a "true" Samoan or Niuean or Tongan coincides with the arguments that to have one's language, one is truly of that culture (1998). This idea of being a "true" Samoan reinforces what Ete (2009) and Unasa (2009) have discussed in regard to individualism vs collectiveness, fa'a Samoa vs fa'a niusila.

The discussion of identity and the interconnectedness of language, culture, heritage and traditions and how one views their own identity when there is a disconnect to one or several of these elements is mentioned within The Location of Culture (1994) by the scholar Homi Bhabha, who is referred to by Unasa (2009) in Su'esu'e Manogi (Tamasese, 2018).

Unasa (2009) reflects on Bhabha's idea that identity is a vernacular cosmopolitan translating between cultures and re-negotiating traditions from a point of "locality" (p.358)

Bhabha (1994) is not far off from describing what is happening in Aotearoa in regard to negotiating one's identity. The role that language plays to one's identity however is emphasised through the works of Fishman (2001), Weedon (1997) and Bourdieu (1977). Fishman (2001) states that language and ethnicity are tangibles features of identity whilst 
Weedon (1997) believes that it is "through language that a person negotiates a sense of self within and across a range of sites at different points in time".

Weedon (1997) goes on further to explain that is through language that one can be granted access or denied access to social networks. Bourdieu (1977) promotes the idea that every time someone speaks negotiation is taking place. Negotiation and renegotiation of one's sense of self in relation to the larger social world.

Gender, class, race, ethnicity, sexual orientation are elements that are all implicated within this negotiation of identity. Weedon (1977) also touches on the importance of understanding relationships in connection to one's negotiation of their identity. "A person's identity must be always understood in relational terms; one is either subject of a set of relationships (position of power) or subject to a set of relationships (position of reduced power)".

Arapera Ngaha (2005) wrote that language loss or the diminished use of language reduces the ability to express your identity in culturally appropriate ways. Through her study "Without the Reo who am I?" Ngaha (2005), discusses the importance of the reo and the power in which te reo Māori enables Māori to be able to describe what it means to "be" Māori, "do" Māori and "know" Māori. Understanding of Mātauranga Māori through the reo is essential not only as it is a key grounding to how Māori define themselves, but also it is seen as "the vehicle by which our culture is best transmitted".

Ngaha's work highlights that eighty two percent of the participants saw genealogy as essential to their identity, forty percent saw tikanga, connections to marae and land and less than thirty percent believed their heritage language was essential to their identity as Māori (2005). Hunkin, (2013) shared that Samoans were no longer viewing identity and language as interconnected.

Does this mean that language is becoming redundant for the new generation? Is meaning, belonging and identity being sought through different avenues? Or do we need to change the direction of the discussion to better understand why identity and language are being viewed as separate entities?

Raising the point that through the reo, relationships are strengthened. Hunkin (2012) is quick to reiterate that one's 'Samoan-ness is rendered redundant if one is unable to articulate the nuances of that Samoan-ness, most of which are best captured and made 
apparent through the Samoan language -Samoan terms and expressions. Hunkin follows on that it should be noted, although the language may change to become more accommodating to the newer Samoan generations there is no requirement for the entire linguistic system to be done away with (2012).

Much literature, research work and writings have explored the connection between a persons' identity and language. If what we are seeing is a change in perception of what it may mean to be Māori or Samoan or Pasifika, then how do we ensure that the language will still be alive through the next generations? 


\section{Chapter 3 Method}

In this chapter I will discuss my initial choice to use the Talanoa research methodology and how, from the early stages of this work, I saw the need to create a different methodology, one that was more suited to this work. I called this the O le Filiga Afa methodology.

\subsection{Introducing Talanoa}

Various interpretations of Talanoa exist within both academic research and every day conversational contexts (Tanufa'i, 2016). In this chapter I will focus on Vaioleti's (2006) and Halapua's (2008) work and their re-interpretation and use of Talanoa as both a form of research methodology and as an act of conflict resolution used within the Pacific.

Talanoa is a term that has been loosely translated as a method of focus group or individual interview discussions and has been interpreted in several different ways throughout academic literature (Tanufa'i, 2016). The overall embodiment of Talanoa across Tokelau, Tonga, Samoa and Fiji, according to Miller (1996), is that it is face-to-face communication which can be either formal or informal. Vaioleti's (2006) interpretation of Talanoa is explored through the break down and literal translation of the word Tala (to tell, relate and command) and noa (of any kind, ordinary, nothing in particular, purely imaginary or void).

Thus leading to the notion that Talanoa can be a conversation about nothing in particular, or with no purpose or meaning (Vaioleti, 2006). Whilst Halapua's (2008) interpretation carries similar sentiments, he relies on the breakdown and literal translation of the word Talanoa, reconstructing Talanoa to be rooted in solution-based dialogue which engages and resonates with one's mind and heart.

\subsubsection{Talanoa as a research method}

Vaoleti puts forth the case that Talanoa can be used as a research method in order to gain real and pure narratives (2006). This is an attempt at decolonising research through the use of Pacific Indigenous research epistemologies (Tunufa'i, 2016). Tunufa'i questions whether this attempt is misdirected due to Vaioleti's personal interpretation of Talanoa contradicting the idea of Talanoa being used to gain important insight into Pacific people's realities. 
Whereas Halapua (2008) is referenced during the 2001 Fiji coup, where he asked leaders to consider gathering to simply "Talanoa". The meeting was seen as favourable as the agenda-less focus implied that conversations to take place would be guided by the leaders themselves, providing a space to create agendas with agreement from all parties working towards a resolution, discussing matters of the heart, of the peoples of the nation.

\subsubsection{Example of Talanoa in public conversations}

The common use of Talanoa as a reference 'to talk' can be seen in many public spaces. A quick Google search of "Talanoa" results in many examples of the term being used outside academia (community Po Talanoa, Climate change Talanoa (AvaNiu Pasifika, 2019; UNFCCC, 2019).

\subsubsection{A problematic use of Talanoa}

The liberalism around the metaphor of Talanoa can be problematic as there is no end to the meanings and interpretation. If there are no boundaries or rules, then how can one guarantee that both Pacific and non-Pacific researchers will know how to use such a method and concept appropriately? How can we be sure that Talanoa itself is an adequate research method?

The shared understanding of Talanoa throughout Pacific nations (Miller, 1996) alongside the new purpose of Talanoa for both Pacific and non-Pacific researchers (Tunufa'i, 2016), borders on the verge of becoming a "go to blanket method" for Pacific research. It can be reinterpreted to fit the context of the researcher, and does not ensure critical analysis, discussions or clarity in the use and the interpretation of Talanoa as research method (Tunufa'i, 2016).

\subsubsection{Talanoa and the Current Research}

When I was visiting my father's sister who is Tongan, I asked her what her understanding of the term Talanoa was, as I was interested to hear what Talanoa means from a Tongan family member after reading so many different interpretations. My aunt laughed and said that what we were doing at the moment was Talanoa; it is to gossip or talk about meaningless things. When I explained that I was considering using this term as a basis for my research method, I was asked if the conversations being had with participants were 
meaningless. This question emphasised my own struggles with using the term Talanoa for research purposes.

If what I am talking about with participants are matters close to the heart, according to Halapua (2008), this is an element of Talanoa. But what must not be cast aside is the elusive, metaphorical and nuance filled nature of the Samoan language (Tamasese, 2003) and continual use of Talanoa places me in a space of contradiction of de-valuing the purpose of the research participants contributions.

Furthermore, Talanoa requires no observation of boundaries regarding age, gender, space, relationship status or spirituality (Vaioleti, 2001). There is an unspoken assumption that meaningful or pure knowledge can be gained through Talanoa. That boundaries and responsibilities are not valid or key to research, however, boundaries, care and respect are essential to, and inform this research work.

The questions used in this research were purposeful and guided conversations with participants. The discussions were not random or meaningless. The maintaining of relationship boundaries between myself and participants, and participants to one another, were essential to this work.

\subsubsection{Key finding of the research process}

It took careful thought, on-going discussions with Elders and cultural experts, and planning and re-planning to ensure this work was effectively carried out. The Talanoa approach was not used because I felt it did not align with the efforts and works of leading Indigenous academic researchers, experts, community elders and leaders' work in decolonising research epistemologies and paradigms.

One of the problematic findings of the research was the nature of Talanoa being too big a space, the lack of a demarcation point where it would end and how to effectively ensure a solution-based premise of this research was possible. Sitting within the void of noa was queried and from this the Afa Method was born. It must be stated that this is my own interpretation of using Talanoa within my research context, and I mean no disrespect for those who do choose to use Talanoa as a research method. I found the Afa method was the best way to "unclutter the clutter" (Tamasese, 2005).

\subsection{Research design}


The research design-methodology that I have used for this research project is $\mathrm{O}$ le Filiga Afa, a culturally derived research methodology that best represents my own Samoan sense of both understanding and undertaking the research process. O le Filiga Afa is the result of efforts to create a research process that is culturally and contextually appropriate.

The method of data collection included focus group and individual one-to-one discussions. Data was gathered through narrative discourse and analysed through thematic and discourse analysis.

\subsubsection{Introduction of O le Filiga Afa Methodology}

The Afa Method is a research methodology that follows the process of making Afa otherwise known as Coconut sennit / sennit braid / coconut fibre rope "the most important single article in Samoan material culture" (Buck, 1930, p. 236). Afa was used in every aspect of Samoan living - industrial use, fishing, housing, cooking utensils even tatau (Percival, 2012).

The process of making 'afa mirrors the metaphorical stage of the research process in which I undertook in this study. The 'afa method involves accountability of the researcher, it carries a sense of purposefulness at all stages, and is grounded in the important understanding of the spirituality that encompasses time, space and place. In this section I will explore all three elements mentioned, followed by the application of the research process.

\subsubsection{Purposeful nature of O le Filiga le Afa}

There is great purpose and intentionality in each stage of the 'afa making process. Prior to the physical process, the purpose is defined to determine the type of Afa to be produced.

Deep thought and consideration are given at each stage and it extends beyond the present and looks to the future. This includes consideration of the sustainability of the process, durability and functionality and each stage works in sync with the stages to come.

In the storing of the Afa great care is taken to reveal the Afa makers beautiful patterns, design and skills. The designs are geometric and mathematically-calculated and precise. There is a systemisation to the process which is beautiful to the eye and lifts one spirit (personal communications, Tamasese 2019). 


\subsubsection{Collective Accountability}

The 'afa process emits a sense of accountability, as the 'afa that is produced reflects not just the maker, but the family, ancestors, village and land that the 'afa originates from. The knowledge and skill of 'afa making was not an individualised craft. It's sustainability and survival relied on the Samoan collective.

Afa is an artefact of the past present and future, a once vital element to the harmonious living of Samoans, used in ceremonious times and for everyday use, the purpose of 'afa went beyond the present. Afa's strength, durability and quality largely determined the sustainability and use of the object it was intended for (personal communications, So'o, 2019).

The process of 'afa making is an intimate process in which the choice of the niu, the process of pounding and sunning speaks to the quality of the 'afa. Each stage of the 'afa process has a Samoan concept which can be metaphorically translated to other aspects of life. These concepts open one's mind to much more than to what is on the physical level (personal communications, So'o, 2019).

The making of the Afa is complex, just as research should be more than a completion of tasks to achieve an academic purpose.

\subsubsection{The then is the now and the now is the then}

The complexity of the "then is now and the now is then" highlights the interconnectedness of the generations and this is a collectivity that continues into the future, telling a story of craftmanship, skill, knowledge, and history.

As I sat and listened [to my uncle] discuss the process of making 'afa, he talked of the vital and direct relationship: between land and being, between maker and 'afa, and through the essence and energy that enters and sustains the process. The choosing of the right materials requires care and delicacy and careful thinking which leads you into a state of diligence. It opens up a space of divergent interconnecting timing and is defined by a grounding assumption that this carefulness and beauty requests the collective from which they originate. 
The service of land highlights the interconnectedness of the relationship between humanity and environment, simultaneously going beyond the present and (also) connecting to the past.

This notion compliments the works of Lavelle (2014) when discussing Indigenous research methods. Supporting the argument that community research should be based on the idea that research is not momentary or a one-time commitment: it is a lifelong commitment and relationship that is established and strengthened over time. (Noting that) Even years after the research project has been completed, should the community you worked with call on you, you should assist them in whatever way you can.

\subsubsection{Spirituality of the process}

The spirituality (purposely not defining spirituality because it is so fluid - subject to each person's frame of reference and interpretation) of a process is reliant on four relationships, these are.

- Relationship to land

- Relationship to ancestors, genealogy, language, and culture

- Relationship to people in terms of justice and love

- Relationship to Atua God

Lima lelei is the careful enacting and embodying of the above four spiritual relationships connecting the present to past and to future generations. (Tamasese \& Parsons, 2019).

\subsubsection{Lima lelei}

"Lima lelel" if the 'afa is strong, well made and beautiful than you would often hear the phrase "lima lelei" meaning their work with their hands is beautiful. The measuring rod that was used was not driven or guided by the monetary value but by how beautiful and practical the end product was.

Through this the gathering of spiritual meaning accumulates as patience and careful thought has gone into this process. The quietness and focus that occurs in the last stage Filiga le 'afa is a process that becomes an extension of you, your 'āiga and nu'u creating a life force of its own.

The sacredness that surrounds a physical object is encapsulated in the process of becoming a timepiece that symbolises the interweaving of past, present, and future generations (personal communications, Taimalieutu 2019). 


\subsubsection{Space and Place of O le Filiga le 'afa}

Each village in Samoa may have had its own traditions and ways of making 'afa, Afioga Ra'amalefolaga Agafili La'au Tuitolova'a talks of the final stages of making 'afa and the ritual that followed this process in his own village. When the fishermen of the village would embark on a shark fishing expedition, the Matai (chiefs) would gather in a house chosen for braiding. As the fishermen departed, the group of Matai's would commence the plaiting of the sennit (Fili le 'afa) whilst simultaneously praying for the safe return of the fishermen.

The fishermen would be at sea for three to four days and on the fourth day braiding and praying would halt and all attention was focused on the sea. The group of Matai would watch the Ocean waiting for the returning shark fishing expedition.

In the last stages of completing the 'afa, it is important to note that space and time carry great significance. Afioga Ra'amalefolaga Agafili La'au Tuitolova'a concludes his story by re-iterating that moments require their own space and time - there is a time of prayers and there is a time for outcome.

A full description of Afa as a metaphor and the embodiment of the research process will follow on from section 3.2.1.7 


\begin{tabular}{|c|c|}
\hline $\begin{array}{c}\text { The Metaphor as Research } \\
\text { Methodology }\end{array}$ & $\begin{array}{c}\text { The Enactment of the Afa Metaphor as a } \\
\text { Samoan / Pacific Research Process }\end{array}$ \\
\hline $\begin{array}{l}\text { Toli le niu - Choosing of the Niu / } \\
\text { Coconut }\end{array}$ & $\begin{array}{l}\text { Selection of research topic } \\
\text { - Thinking, canvassing and planning of a } \\
\text { research topic to be is occurring. } \\
\text { Questions such as relatability, } \\
\text { accessibility and appropriateness of } \\
\text { research topic are questions that need } \\
\text { to be considered seriously before } \\
\text { embarking on a research journey. } \\
\text { - Talking with family members, potential } \\
\text { supervisors and community leaders } \\
\text { are also a part of this process before } \\
\text { taking on such a task. } \\
\text { - Selection of methodology } \\
\text { Selecting an appropriate methodology } \\
\text { to fit the context of the research }\end{array}$ \\
\hline Husking & $\begin{array}{l}\text { Breaking down / defining the process } \\
\text { - What is needed to carry out this } \\
\text { research? } \\
\text { - How will this research be achieved? } \\
\text { - What resources tools, and experts can } \\
\text { I call on to guide me through this } \\
\text { research process? } \\
\text { - Am I the right person to be conducting } \\
\text { this kind of research? }\end{array}$ \\
\hline Taomaga- Soaking of the husks & $\begin{array}{l}\text { The Break down in preparation of data } \\
\text { collection }\end{array}$ \\
\hline
\end{tabular}




\begin{tabular}{|c|c|}
\hline & $\begin{array}{l}\text { - } \text { Preparatory steps before data } \\
\text { - } \text { Thellection and analysis stages } \\
\text { - The perspectives that will be needed } \\
\text { - The gender and age of people that will } \\
\text { - } \text { be interviewed } \\
\text { - The resources needed } \\
\text { - Canvassing of environment }\end{array}$ \\
\hline Sasa le pulu - Pounding process & $\begin{array}{l}\text { Data collection } \\
\text { - Data is collected through either one- } \\
\text { on-one semi-formal interviews / } \\
\text { discussions or focus group } \\
\text { - Space for meeting is decided upon by } \\
\text { both participants to ensure comfort and } \\
\text { privacy Sharing of experiences and } \\
\text { narratives of participants } \\
\text { - Guiding questions are asked to prompt } \\
\text { the conversations } \\
\text { Sessions are audio recorded with } \\
\text { notes being taken also by researcher } \\
\text { (me)Topics of conversation are guided } \\
\text { by both me the researcher and } \\
\text { participants } \\
\text { Sharing of narratives and experiences } \\
\text { of participants }\end{array}$ \\
\hline $\begin{array}{l}\text { Matofi - singular sennit fibres } \\
\text { separated as a result of the pounding. }\end{array}$ & $\begin{array}{l}\text { Thematic analysis } \\
\text { - Identifying of themes that have arisen } \\
\text { from the data collection }\end{array}$ \\
\hline $\begin{array}{l}\text { Faata'a - Rolling of two or three Matofi } \\
\text { to create a thicker strand of sennit. }\end{array}$ & $\begin{array}{l}\text { Continual Thematic analysis } \\
\text { - Unpacking and exploring of the themes } \\
\text { presented } \\
\text { - Understanding and unpacking of } \\
\text { factors that contribute to the themes }\end{array}$ \\
\hline
\end{tabular}




\begin{tabular}{|l|c|}
\hline & $\begin{array}{l}\text { - } \text { Bringing together of all the themes to } \\
\text { understand the interconnectedness } \\
\text { and interlinking of the narratives and } \\
\text { themes presented }\end{array}$ \\
\hline Filiga le Afa - braiding of the Afa & Ultimately working to understand the \\
& bigger picture
\end{tabular}




\subsubsection{Toli le Niu / Choosing of the niu - Selection of research topic and methodology}

Toli le Niu is the process of selecting the right Niuafa - the land is canvassed, the tree's sought after and the Niu's selected upon. Selection of the Niu can be likened to the process of selecting a research topic and methodology. Careful consideration is taken when selecting the Niu's that will be used to make Afa similar to the process of choosing a methodology to fit the context of the research.

Many Pacific research frameworks exist already Fa'afaletui, Talaloto, Inati and Kakala, (Tunufa'i, 2016) to name a few, however, there is no guarantee the framework will be fitting to the nature of the research.

The intention behind the use of Afa is predetermined before the first stage of harvesting Niuafa begins. This will dictate the length, strength, width, colouring, and storage of the 'afa. The purpose of the research must be taken into great consideration as the methodology will determine the quality of the research.

Questions such as:

- What topic is needing further research to better my community?

- Why is this topic needing to be explored and researched further and to whom does this kind of research topic hold me accountable to?

These questions guided my thoughts and conversations with elders, thus providing a starting point for my research.

"Samoan language maintenance in second generation households in Aotearoa" was decided upon because I can relate to this group of peoples. I am second generation Samoan born and raised in Aotearoa. My relatability and knowledge of and towards this particular group allows me insight and guidance of how to carry out such research.

The selection of the Niu goes beyond selecting of a method, and research topic. It is the definitive moment of understanding and laying out the purpose in which this research will serve and beginning the process of undertaking those steps to ensure that at each stage of the research the purpose of the research is the focal end point. 


\subsubsection{Husking of Niu - Defining process}

When husking the niu, Pulu (coconut husk) are pulled from the coconut seed and placed in a large 'ato (woven flax basket) in preparation for the next stage. This process is likened to the breaking down and defining of the requirements necessary to carry out the study.

The pulling a part to lay bare the nut is likened to the identifying of the critical aspects that must be considered in order to best ensure the practicality and relevance of the methodology.

Questions included:

- How will this research be carried out?

- Whose perspectives do I need. - Young and elderly?

- Focus groups, Individual interviews?

- Men and Woman or just Woman?

- New Zealand born only or Samoan diaspora?

- What tools and experts can I call on to guide me through this research?

- Do I have access to a community of Samoan second generation living in Aotearoa?

- Is this an appropriate topic to take on?

- Who will this research serve?

- What is the purpose of this research?

These questions allow for the breakdown of the process to be more definitive and clearer in the direction of the study.

The advice and guidance received contributes to adjusting of my own research topic and process where necessary, reaching out and engaging with potential participants early in the process is important to allow time to explain the purpose behind the research, time for participants to deliberate whether they would like to participate and ask any questions that could help with my own shaping of the research. 


\subsubsection{Taomaga / Soaking of the husks - Breakdown in preparation for data collection}

The Taomaga is the soaking of the pulu (husks) in either the sami (sea) or swamp depending on both access to sea or swamp and purpose of the 'afa. If the 'afa needs to be stained black it is buried in the swamp as the mud acts as a dying process. If staining is not required, the baskets of pulu are placed into the sea with large rocks placed on top securing the basket down. The soaking / dying process takes from up to six to ten weeks.

One of the complications that can occur with research is the rushed nature that can come from the data collection process due to the pressure of deadlines, funds and timelines that must be adhered to. The Taomaga process is the likening of the relationship building and strengthening between myself and participants.

An assumption that can be easily made due to having insider status (Kanuha, 2000) is the idea that trust between myself and participants would be immediate. Hence immediate collection of data can commence.

The process cannot be rushed, just as I cannot rush my family members or elders to provide me with guidance and advice immediately, nor can the dying / soaking process of the 'afa be rushed. There is a process, trust must be built and with what may seem the slow nature of this process comes the understanding of allowing the community, leaders and elders and participants to be a part of the research not just a temporary fixture until I am able to gain what is needed.

\subsubsection{Sasa le pule / Pounding - Data collection process}

Once the pulu is ready for harvest it is pulled for the Ocean / Swamp and the process of pounding or beating the pulu begins. A square like stool with four legs called a Meleke is used to sit on placing the pulu in front of him or her. Using a Palatua (baton like stick) the pulu is beaten, until the coconut fibres separate from one another becoming singular strands. These strands are called Matofi. Once the maker is satisfied the Matofi is placed in a barrel of ocean water to rinse off any debris and placed in the sun to dry out ready for the next stage.

This process is analogized to the data collection stage. 
The beating of the husk is a focused activity - the focus of this activity can act as an analogy for the focus that is required for both participants and researcher. The guiding of the pounding requires intent and focus to ensure accuracy and efficiency. The guiding of the researcher requires the same level of focus, navigating the discussions and stories that are shared and so too do participants carry the same level of intentionality.

Choosing what narratives to share, listening, and reflection occurs throughout the focus group and one to one discussion.

Separating of the Matofi as a result of the pounding equates to the identifying of reoccurring themes and recognizing the contributing factors of these themes preparing for the thematic analysis stage to come.

\subsubsection{Faata'a / Binding of Matofi - Thematic analysis}

Once the Matofi have dried in the sun, it is gathered and prepared to become Faata'a. This requires the gathering of Matofi in groups of two or three, bound by another Matofi and then followed by the act of mili - rolling, in order to bind the Matofi together. The rolling action usually takes place on the leg or upper thigh of the person sitting crossed legged on the ground. The result is a thickened strand called Faata'a, which will then be braided with two (or more depending on the ply required) Faata'a together to make a long strong sennit / 'afa.

The Faata'a process resemble the thematic analysis of the data collection that occurs. Becoming familiar with the themes, coding and generating of themes, reviewing, defining, naming and lastly writing up occurs during this process of analysis.

The stripping and unpacking of the husk down to its singular fibres, to the gathering and rebuilding of the singular strands to form a thickened strong rope. Metaphorically speaks to the unpacking furthering beyond surface level explanations in order to provide in-depth insight to the status of Samoan language in Aotearoa. 


\subsubsection{Filiga le Afa / Plaiting of sennit - Findings and Discussion}

Filiga le Afa is the braiding of Faata'a to create long ropes of 'afa. I have heard various descriptions of when and where Filiga le Afa would take place such as, during village meetings Matai - chiefs would plait 'afa as they deliberated and discussed matters of importance.

Another example is during times of prayer whilst waiting on the return of a shark fishing expedition. Whichever the case a commonality that is shared between these different scenarios is the quiet focus, intent, space, and place that was dedicated to the act of Filiga le 'afa.

A proverb birthed from Filiga le Afa "O le aso ma le Filiga, o le aso fo'i ma le mata'igatila" conceptually translates to the idea of carrying the same careful consideration and thought into one's words and actions. The impact of words carries heavy weight prompting a slow considerate process. The rush of words in a haste to respond can carry great consequences, Fili of the 'afa is the slowing down, the careful choosing of materials. It becomes the leader of thought the process of thinking. The plaiting of the Afa is the interweaving of all the different steps taken to get to a point of presenting the findings and discussion.

\subsubsection{Wrapping of the Afa - Recommendations}

The final stage of making of 'afa is storing of the 'afa, the intention behind the use of the 'afa determines the shape, size and way in which it will be stored. This final stage is likened to the recommendation that come from the research. Recommendations at family, community, and government level in order to best serve the Samoan community better in particular around the revitalisation and maintenance of Samoan language in Aotearoa. 


\subsubsection{Narrative Inquiry}

Narrative inquiry has been described as an umbrella term used to capture the relationship between personal and human experience and cultural context (Clandinin and Connelly, 2000). In simpler terms, narrative inquiry is the study of human experiences through storytelling. An approach that requires in-depth analysis and exploration of lived realities.

Narrative inquiry provides insight into the core concepts, assumptions and underlying insights that are presented throughout the stories and experiences shared (Bell, 1995, 1997a, 1997b; Colne, 1992; Golombek, 1998). Pushing for understanding but also allowing room for researchers to present the experience holistically in all its complexities and richness that accompanies shared narratives (Bell, 2002).

Being able to relate to the participants allowed room for guiding questions to be asked in a non - intrusive manner which in turn provided moments of learning and self-realisation. Highlighting the temporary notion of experiences, recognising that understandings of people and events are always open to change and shifting in interpretation (Bell, 2002).

\subsubsection{Researcher reflexivity}

Reflexivity: a) the process of critical self-reflection on one's biases, theoretical predispositions, preferences, b) an acknowledgement of the inquirers place in the setting, context and social phenomenon he or she seeks to understand and a means for a critical examination of the entire process.

O le Filiga Afa method coincides with research reflexivity - critical self-reflection and examination of the research process (Schwandt, 1997). Collective accountability and the act of careful thought and consideration of all parties required constant self-reflection. Selfreflection of personal biases, my position as a researcher in the different contexts I entered. The power imbalance between myself and participants and need for continual critical analysis at each stage of research. This was encouraged further by Samoan elder leaders, posing four questions as a reference point of researcher reflexivity.

1. How will this research benefit Pacific peoples (primarily Samoans)?

2. What are the solutions that have come forth already?

3. How will this research increase proficiency?

4. How might this research take away from Pacific peoples specifically Samoan peoples? 


\subsubsection{Data Collection Method}

\section{Agreed method of semi structured interviews}

To best allow the data to be grounded in participant narrative (Schilling, 2013) collection of data was decided upon through semi structured interviews. Which allowed for integration of both open-ended and theoretically driven questions. The open ended-ness of the questions created a space for narration of experiences. The theoretical nature of the questions was deliberate, connected to the purpose of the research and reliant on my own knowledge and experiences to best support the unfolding narratives ( $p 47$ ).

Six individual semi structured interviews and one semi structured focus group of six participants were carried out. Upon reaching out to participants to assess interest in participation some participants expressed a desire to contribute collaboratively. Heedful of adhering to the Samoan principle of fa'aloalo (Va'ai, 2014) both options of either one on one with myself or to partake in focus group was offered to participants.

Method of focus group benefits sensitive topic, as participants can decide on what they want to contribute without feeling pressure they must provide an answer to the questions asked.

A benefit of group discussion was participants could choose when they wanted to contribute without feeling pressure they must answer or contribute. Through listening to other participants share their own experiences, an opportunity for participants to gain more clarity around the guiding questions and thought around how they would like to answer and contribute to the group discussion was provided.

It is important to acknowledge potential for conformity to group atmosphere (Adler \&Clark, 2011) could occur in the focus group which was also another reason as to why one on one was provided as an option for data collection. 


\subsubsection{Participants}

The criteria for participants included that they had to be Samoan, where at least one parent is of Samoan heritage. They had to have been raised most of their life here in Aotearoa, if not all of their life up until now. They had to be either first, second or third generation Aotearoa Samoan. There were no criteria for having to be able to speak Samoan. Understanding the factors that surrounded their heritage language proficiency and how this impacts their wellbeing and sense of identity in Aotearoa was what this study is more focused on.

Participants were approached through my own personal social networks. Although the intention was to provide a collection sample that consisted of an equal number of both women and men, it was difficult to secure time slots to meet up with several potential participants due to the time of year being so close to Christmas.

Limitation of unbalanced gender ratio raises the question as to whether the shared experiences is also representation of Samoan male second generation.

An advantage of knowing participants on a personal level was the ability to enter discussions with a prior understanding of background and cultural context. Awareness of boundaries and Samoan protocol that assured comfort and observation of these boundaries. Trust between myself and participants had been established, influencing the openness of participants and willingness to share experiences.

Two limitations that may be born out of knowing participants previous to the research project are hesitation to share personal information in fear of judgement or critique of one's family or experiences. And the assumption that I understood the experiences being shared, leading to incomplete sentences based on the mutual agreement assumption that I knew what participants were referring to.

\section{Samoan speaking participants SSP}

Samoan speaking participants referred to themselves as being fluent in Samoan. This was described as having great confidence and skills in both speaking and comprehension of Samoan language. 


\section{Non-Samoan speaking participants NSSP}

Participants who fell under this category described themselves as having either a) little to no fluency of Samoan b) having high comprehension but limited speaking and reading skills or c) limited in both comprehension and speaking skills.

It should be noted that the level of one's confidence was a large contributor to whether participants viewed themselves and Samoan speakers. For some participants they had a high level of speaking and comprehension however, their confidence in their ability to speak Samoan took precedence. Often leading to participants viewing themselves as nonSamoan speakers.

The table below introduces the participants, age, gender they identified as and context of background.

\subsubsection{Participants table}

\begin{tabular}{|l|l|l|l|l|l|l|l|}
\hline Name & Age & $\begin{array}{l}\text { Woman } \\
\text { / Man }\end{array}$ & $\begin{array}{l}\text { Both } \\
\text { parents } \\
\text { Samoan }\end{array}$ & $\begin{array}{l}\text { Raised in } \\
\text { Samoan } \\
\text { speaking } \\
\text { household }\end{array}$ & $\begin{array}{l}\text { Born in } \\
\text { Aotearo } \\
\text { a }\end{array}$ & $\begin{array}{l}\text { Raised } \\
\text { with } \\
\text { Samoan } \\
\text { grandpare } \\
\text { nts }\end{array}$ & $\begin{array}{l}\text { Identify } \\
\text { Samoan } \\
\text { speaking }\end{array}$ \\
\hline Participant 1 & 27 & W & Yes & No & Yes & Yes & N \\
\hline Participant 2 & 40 & M & Yes & Yes & Yes & No & Y \\
\hline Participant 3 & 25 & M & No & No & No & Yes & N \\
\hline Participant 4 & 26 & W & Yes & Yes & Yes & No & N \\
\hline Participant 5 & 26 & W & Yes & Yes & Yes & Yes & Y \\
\hline Participant 6 & 29 & W & Yes & Yes & Yes & No & Y \\
\hline Participant 7 & 22 & W & Yes & Yes & Yes & No & N \\
\hline Participant 8 & 26 & W & No & No & Yes & No & N \\
\hline Participant 9 & 26 & W & No & No & Yes & No & N \\
\hline Participant 10 & 24 & W & No & No & Yes & No & N \\
\hline Participant 11 & 25 & W & No & No & Yes & No & N \\
\hline Participant 12 & 27 & W & Yes & Yes & Yes & No & N \\
\hline
\end{tabular}




\subsubsection{Focus Group}

\section{Selection of focus group participants}

The careful selection of participants was deliberate, considering factors as to whether participants could speak Samoan, born and raised in Aotearoa, and whether they were of second generation were all important factors to consider when compiling a list of participants to reach out to.

The choice to include participants who considered themselves fluent and strong within their gagana alongside participants who did not view themselves in the same manner was decided upon to represent the varying factors that contribute to answering the aims of this research.

When putting together the focus group, a point was made to ensure that the focus group was made up of either speakers or no-speakers, a mixture of both I believed would not establish comfort. Fear of judgement from Samoan speakers, or feelings of inadequacy and anxiousness was a notion I was aware of from personal experience and a question that was often raised when reaching out to potential participants. "Will there be other Samoans there and will I have to speak Samoan? "Can I be part of the group that can't speak Samoan just in case"? were often the first two questions I was met with when explaining the purpose for the research.

\subsubsection{Creating a space of comfort}

Opening up a space to share one's stories was heavily dependent on the locality of the gatherings, comfort and scaredness around space and place.

Gendering of the research was purposeful. The focus group was made up of all women a decision that coincided with the importance of observing the boundaries of the relationships which exist between woman and man, contributing to the comfort and ease of the space for participants. When participants arrived, they were greeted warmly and offered a beverage. Once settled in, they were given a consent form, information sheet and a sheet of meanings of the different terms that could be used throughout the conversations. 
Once everyone had arrived, lotu (prayer) was said, it was important to acknowledge the interconnectedness of Spirituality, Prayer and Religion within the Samoan cosmos (Tamasese, 2005).

Next a meal was shared between all participants and myself, in a Samoan context, food is not just a meal that you share to sustain your body. It is a moment of stillness and acknowledgment of the relationships between one another.

Upon calling people to gather, one must be ready to provide sustenance, shelter and comfort.

During this time of eating, participants shared with one another their thoughts, questions and ideas around the topics that were to be discussed. Upon completion of meal, we sat for another half an hour while I shared my own journey of undertaking this topic of research and in the process explaining the importance of their contribution. This in turned contributed to relatability between myself and participants. Exposing my own vulnerabilities ensuring participants that I would not ask them to participate in anything that would make them feel uncomfortable, embarrassed or give reason to be nervous.

A point was made when forming the focus group to be made up of participants who shared similar levels of confidence in Samoan both speaking and comprehension to appease any fear of judgement or feelings of inadequacy that may occur. Repeating to participants that if at any stage they feel uncomfortable or do not want to continue they are welcome to leave the room or ask for a moment to pause and turn off the recorder.

\subsubsection{Sasa le pulu - Data Collection}

Once everyone had acknowledged they were ready to start, the audio recorder was turned on. The discussion / Sasa le pulu session was prompted by starting with the first question line to start the conversations of "what does it mean to be Samoan in Aotearoa". Reasoning for this opening was to prompt thought and discussion of participants own experiences of being Samoan and raised in Aotearoa. I made a point to ask this question again at the end of the session to allow participants to add onto or change their previous answer. 
There were no time restrictions to allow for easy free flowing conversation without worrying that we were going over time.

Everyone had a turn at answering the questions, and before I moved on to the next question line I would ask if anyone else wanted to contribute anything more. At times there were long stretches of silence in which I made a point of not interrupting this silence as it was clear to me that the participants were deep in thought and needed time to think about the questions that were asked. What I was asking of the participants was to open up to not just myself but also to the rest of the focus group. It was important that I allowed participants the time to think about what they wanted to contribute and that they were not rushed into answering.

As we moved deeper into the conversation it was interesting to note that the discussion was crossing over, and as participants felt more comfortable to share their stories and knowledge with one another they became more open. The silences became shorter, and there was little prompting from my end to encourage discussion.

\subsubsection{Participant feedback}

The focus group came to an end when the last question line was asked and answered. I asked once again if anyone had any more thoughts or anything else to add to the discussion or any of the past questions that were asked. When all participants had agreed they were satisfied with the contributions they had made to the discussion, the audio recorder was turned off.

Once the audio recorder was turned off, participants continued to discuss how they felt the session went, what they enjoyed about the session and what they were surprised at learning about both themselves and others by the end of the session. During this time, I asked for feedback from the participants, and I asked about what their thoughts were on the process.

It was in the focus group that participants pointed out they would have liked to have introduced themselves and the villages they came from before we started the interview. In my effort to ensure that all identity was kept safe I did not think to ask participants to 
introduce themselves in a large group, which as I reflected on this, I realised was a big mistake.

To rectify this, we all went around the room and introduced ourselves as in who our parents were, what villages we came from. I made an effort to ensure that with each interview I held moving on from the focus group started with introducing myself to the participant and asking them to do the same.

In the bid to conform to what I believed to be ethical research standards I felt conflicted when asking participants to introduce themselves and their 'âiga, as I believed it was best to get straight into the semi structured interview. Concern that participants would feel too exposed by asking them to introduce themselves and the villages they hail from was a mistake.

I also asked if they found the questions too abstract, intrusive or if they would change the way in which I asked the questions or the placement of the questions. Taking notes of the feedback, I thanked the group once again for participating in the study. Offering participants, the option to return for a second session to go through the themes and findings of the data collection all participants were eager to return for a second session.

To close the session of the Focus group a final lotu was said, and mealofa was given to the participants to thank them for their participation and to help with travel costs.

\subsubsection{One-on-one semi structured Interviews}

Both question sets were the same for the focus group as they were for the individual one on one sessions.

The process for the focus group was the same process in which I conducted the individual interviews. The only difference was that the location of the interviews was different for each person. Interviews were held at a café that was agreed on by both me and the participant. It was important that the participant felt comfortable and chose the location due to easy access, privacy and quiet enough to talk without worry of interruption or being overheard. 


\subsubsection{Research Questions}

The purpose of the research was to investigate the current situation of Samoan language in Aotearoa amongst second generation Samoans. To support this investigation, three leading questions were created in a deliberate attempt to best understand the current situation. These three questions were:

1. How do second generation Samoans see language contributing to identity?

2. Where are second generation Samoans using and learning Samoan?

3. Is there a relationship between wellbeing and language shift or / maintenance?

In addition to these three questions, sixteen guiding questions were formed to guide the discussions in relation to the research topic to encourage the flow of narratives in a nonintrusive manner, guiding the direction of participants responses without feeling too regimented or restricted. In most cases however, I noted that very few times did I need to ask these questions directly as they were answered indirectly through the sharing of experiences and narratives. (See appendix I for list of questions)

Each semi structured interview lead with guiding question number 1 (see appendix). The broadness of this questions allowed room for personal interpretation and reflection of one's experience. Focus on the strengths of the Samoan culture and leaving room for participants to share their interpretation and meanings of their identity.

The opening question made space for the data to be grounded in the experiences of the participants, although not directly answering the purpose of the research, the question encourages a generative narrative (Schilling, 2013) that leads to an opening of reflection, personal interpretation and analogy influencing the direction of the narratives.

Before moving onto a different topic or asking the next guiding question I would always ask if there was anything else, they wanted to add before we moved on? Articulating to participants that we can always come back to this point of conversation at any time of their choosing. By asking if there was anything else they wanted to add signalled to me whether they were ready to move onto a new topic of discussion or whether we needed to delve further into the discussion, indicating if participants were wanting to explore understand ideas that they had not considered before entering the discussion. 


\subsubsection{Matofi / Faata'a - Data analysis}

Once data collection had been completed, all audio recordings were transcribed word for word, whilst transcribing I was also taking notes and becoming familiar with the data. Reading through the transcripts three to four times over to ensure make sure the audio matched the transcription.

Once transcripts were complete, I highlighted texts creating "codes" to best describe the content. Through looking at the codes, I started to identify patterns across the data collection and name themes. Once a list had been compiled of prominent themes a second focus group was organised. Once again, the focus group gathered again, looking at the themes generated this second session allowed time for participants to reflect on their own understandings and meanings of the identified themes.

In this session participants gave feedback on whether they agreed with the themes, factors to be considered and what it meant for the

As I transcribed, reoccurring themes were noted down and later explored in more depth. Themes were explored in more depth by looking at each transcript to identify whether the theme was re-occurring, highlighting any quotes or conversations that contributed to the themes - what factors contribute to the themes, how participants have come to understand the themes and what these themes tell us about the future of Samoan language in Aotearoa.

Thematic analysis was the approach in which I took when analysing data - "a method for identifying, analysing, and reporting (themes) within data. It minimally organises and describes your data set (rich) detail. However, it also often goes further than this, and interprets various aspects of the research topic" (Boyatziz, 1998 found in Braun and Clarke, 2006). The use of themes is important when understanding the data as Braun and Clarke (2006) explain, a theme captures something important about the data in relation to the research question.

Each question line acts as a theme when analysing the data, and each time a theme that correlated with a question line came up, this would be noted down. 
Being able to identify themes throughout the data allows for the ability to understand or grasp more clearly what is contributing to the shift in Samoan language, as well as what role this plays in regard to wellbeing and sense of identity. Braun and Clarke (2006) explain that the key of a theme is not always dependent on quantifiable measures, but instead in terms of whether it captures something important in relation to the overall research question.

The data analysis stage can be likened to the weaving of 'afa. The gathering of material preparatory steps undertaken to get to a point of gathering to hear the narratives of the Samoan second generation. The sharing of narratives of language journeys by participants is what leads to the identifying of key themes. Thus, providing a deeper insight as to why the use of Samoan language in Aotearoa is declining. The weaving of all these factors and experiences can be similar to that of art imitating life however in this case it is life imitating the art of fili - weaving. 


\section{Chapter 4 Findings}

4.1 Language, identity and culture are intrinsically interwoven

Lack of value placed on Samoan language within the educational system contributes to the shift of Samoan language.

The narratives shared amongst the participants identified language, culture and identity are intrinsically interwoven. The lack of Samoan language learning and support and value placement throughout the education system had a profound impact on one's sense of belonging.

Participants expressed frustration and concern that their language, culture and identity as Samoans were rarely ever recognised, acknowledged, or seen as a positive strength that is valuable in multiple environments.

The lack of acknowledgement and value was indicated to participants in different ways. Little to no access to Samoan language learning classes or opportunities, lack of continual bilingual educational support and the lack of Samoan teachers or staff were commonly shared experiences.

These indications emphasised a sense of displacement and uncertainty in the worth of their identity and culture thus strengthening insecurities and doubts about language learning skills and place of belonging.

\subsubsection{Little opportunity for Samoan language learning or maintenance}

Samoan language classes or learning opportunities were not an option available to majority of participants throughout their primary and tertiary education.

Participant 2 talked about his mother starting up a Samoan club at his school in response to the need for Samoan language support and Samoan parents' requests for a Samoan club to be formed. A space for Samoan students to come together, learn pese and siva Samoa alongside opening a space to celebrate and encourage practice and use of Samoan language. Sustainability of the club relied heavily on the donated time, energy and resources provided by the Samoan parents. 
Three out of the twelve participants attended high schools in which Samoan language classes were an option made available to students. Participant 3 was the only participant to take the Samoan language classes offered. However, chose to drop the class early into the year as lessons consisted of listening to a Samoan radio station for the entire duration of the class.

A limited quality of language teaching resources and skilled teachers that contributed to participants not taking up the offer of Samoan classes at high school was highlighted once again through participants 10 experience. Her high school offered Samoan as a subject, however a pre-requisite of needing to "know the basics" was required. The requirement leads to participant 10 doubting her language skills fearful of embarrassing herself in front others.

The excerpt below is an exchange in the focus group between participant 10 and 11 .

\section{Excerpt 1:}

1. Participant 10 You had to know the basics. You couldn't go and not know. And me

2. being self-conscious as a teenager, I thought I didn't know the basics, but I did. In my

3. head I knew the basics. But because I thought maybe my basics isn't their basics. So,

4. I didn't take it based off that reason. I didn't want to go in there thinking, 'I know the

5. basics and then I'm sitting there like "oh my gosh I don't know anything (+)" But

6. none of the other languages like French all of that $(+)$ nothing. You could just go in

7. there. But with Samoan you had to know the basics. Because I remember I was

8. interested. Like cool mean! And then I heard that I was like "Oh nah"

9. Participant 11: It could be a reflection on the funding they had on what resources

10. they had. As to what they were actually capable of teaching the students. Maybe

11. they just didn't have the resources to start from the very basics if the student just

12. literally knew nothing. 
Participant 10 points out the strong feelings of self-doubt and inadequacy that go hand in hand with not being a native speaker of Samoan. Fear of being out of her depth appearing incompetent in a language that is so intrinsically connected and rooted in family, identity, and culture. So, if not competent here, also impacts one feelings of position within the family, culture and as a Samoan - a lot more is at stake. Exacerbating one's insecurities and uncertainties.

Emphasis expressed in line nine demonstrates the frustration felt around the pre-requisites being exclusive to Samoan speaking learners. Suggesting a sense of inequity and lack of care toward Samoan as both a language and subject of learning.

The allocation of resources and budget to ensure quality and skilled teaching of Samoan to learners who have varying knowledge and understanding of Samoan is reliant on the value in which the school places on the Samoan language as a subject.

\subsubsection{Lack of continual bilingual educational support.}

The correlation between lack of continual bilingual support from preschool to primary and the sudden increased speed of language shift was evident when participants talked of once being "strong in their Fa'a Samoa".

Out of the twelve participants, seven identified attending ā'oga 'āmata (Samoan Early childhood language learning nest). Three participants indicated they did not need to attend ā'oga 'āmata as childcare was solely overseen by Samoa speaking grandparents or parents. Two participants indicated they were not placed in ā'oga 'āmata however their eldest siblings had been.

All participants acknowledged despite Samoan being their heritage and or most at the time first language. None of the primary schools participants entered offered transitional bilingual educational support, the sudden transition from a Samoan speaking and hearing context to an English only context with little to no acknowledgement of heritage language resulted in Samoan having to take a back seat.

In the next excerpt we hear participant 4 talk about the notion of once being "strong in her fa'a Samoa" 


\section{Excerpt 2:}

1. Researcher: Did you attend Aoga Amata as a child?

2. Participant 4: I did, so apparently when I was little, I was strong in my language. But I

3. just don't understand being strong in my language [...]

4. Researcher: So primary school? Was Samoan ever offered or spoken in primary?

5. Participant 4: No

6. Researcher: Any Samoan teachers?

7. Participant 4: Yeah and it was ${ }^{* * *}$ mum

8. Researcher: Oh, and did she ever use Samoan with you?

9. Participant 4: Only if we're like on the playground or where it was like it wasn't a

10. teaching environment. [!!] She would be talking to us one on one $(+)$ but then also

11. because I was so close with ${ }^{* * *}$. I used to go sleepover, so that's how Miss ${ }^{* * * *}(+)$

12. she would feel comfortable to kind of speak to me in Samoan and (*) I would

13. understand her. But $\left({ }^{*}\right)$ at school she would do it with certain students. So obviously

14. all students were either her nephew, daughter or nieces, I guess [...]. But she was

15. probably the only person where you felt comfortable being a Samoan because she

16. was a Samoan teacher [...]

Participant 4 talks of once being "strong" in her language, indicating she no longer views this as the case. Participant 4's choice of wording indicates her own confidence and feelings regarding how she perceives herself in relation to her language and knowledge of Fa'a Samoa.

Absence of bilingual transitional support from A' 'oga 'āmata to primary school resulted in participant 4 having to assimilate and adopt the English language immediately placing Samoan on the back burner. Highlighting the notion of English being a language of necessity not choice. 
Although Samoan was not spoken within the classroom, from lines nine to fourteen participant 4 points out Mrs ${ }^{* * * *}$ only felt comfortable or safe speaking Samoan when in the presence of Samoan students she knew on a personal basis. Implying the school was neither welcoming nor encouraging of Samoan language.

The presence of a Samoan teacher carried great weight as indicated in lines fifteen to sixteen, participant 4 points out the sense of "otherness" that surrounds being Samoan at her school despite the high population of Samoan students. A sense of discomfort and uncertainty of belonging within the school system is emphasised in lines 15 and 16, and the assurance of belonging is only felt when in the presence of a Samoan teacher.

Lack of bilingual transitional support and lack of Samoan teachers or teachers who were aware of Samoan students' needs and how to best support them regarding maintenance of language is a significant consequential factor that contributed to the shift of Samoan language as noted in excerpt 3.

\section{Excerpt 3}

\section{Participant 12: My mum told me I think I only started speaking English \\ 2. full time [...] when I went to primary school. And that's where I kind of \\ 3. lost it}

\subsubsection{Significant platform Poly Club provided for participants}

Knowing the challenges that were faced by participants within a school context, the question remained - how did participants find a sense of comfort and belonging in a system that most often ignored them? The joining of Poly Club for majority of participants provided a reprieve from the struggles highlighted previously.

Each year high schools around Te Whanganui -a- Tara region gather to showcase and celebrate their Pasifika cultures through song and dance at a Pacific festival. In response high schools would form Poly clubs where Pasifika and non-Pasifika students would come together to learn, practise and perfect Pacific songs and dance to perform at the festivals. Similar to the Tāmaki Makaurau Poly Fest that occurs once a year in Manakau (ASB Polyfest, 2019). 
Participants stated that it was here that they were able to hear their language being spoken, and it was able to be claimed in full.

Poly club provided a space that allowed students to hear not only Samoan but also Tongan, Tokelauan, Kuki Airani being both spoken and sung. Participants expressed a sense of belonging and pride that was felt through being a part of Poly club was the only time they were acknowledged as Pacific students and felt their school cared about them.

Samoan-speaking participants also shared that Poly club was a time when they stepped into leadership roles which came naturally. Teaching and leading the items was one aspect of what was entailed. Organising the times of practices and venues, uniforms, fundraising and negotiating with teachers to allow their school to partake in the Poly festival gave participants a meaningful sense of purpose in a leadership position that they normally would be looked over for. Support from families and parents of the students and leaders of Poly Club was critical to the ongoing sustainability.

For many the only times their leadership skills were recognised by the school or were given the opportunity to take on a formal leadership title and role within the school context was when they became a leader of Poly club.

In the next excerpt we hear from participant 5 talk about what "Poly" meant for her.

\section{Excerpt 4}

\section{Participant 5}

1. I think because the only thing we had was Poly and that was the only time we

2. could show our culture, but it was every two years. Yeah. So, what like every

3. two years you could be a Samoan and we'll acknowledge you. (+) But every

4. pther year we (the school) don't [ $\left.{ }^{*}\right]$ care

The statement of Poly club being "the only thing we had" in lines 1 implies a sense of ownership and belonging in a context in which this was rare to find for Pacific students at her college. 
The use of "only" states that for participant 5 and the rest of her fellow Samoan students no other space existed like this within their school. Implying her educational journey throughout college did not allow room or space for her culture or language to be present. Thus, reinforced further in lines 3 "every two years you could be Samoan".

Signalling feelings of oppression or denial of one's identity placing pressure to assimilate. The use of "could" implies to a certain degree a feeling of powerlessness. Dependence on powerful structures and people within the school allowing spaces as such to exist was inevitable as they're not completely independent of the school, essentially relying on the same racist systems in order to exist.

\subsubsection{Samoan Radio, Music and Newspapers}

The key theme that was made evident when participants talked about listening to Samoan Music, Radio stations and reading of Samoan Newspapers. Was form of connection to heritage language that was within a safe and comfortable environment.

Participant 12 shared with the focus group when reading Samoan newspapers, she would practice reading out loud to help with her pronunciation of Samoan words. Making a point to note that she practiced reading out loud most often when alone. So, to avoid embarrassment of mispronunciation.

Participant 7 spoke fondly of listening to the Samoan radio station as a child with her grandmother. Although as an adult she tends not listen to the Samoan radio as often, acknowledging the consistency of listening to the radio with her grandmother as a child provided an opportunity to learn new terms and words in the comfort and safety of her grandma's home.

Participant 11 makes a point of always listening to and playing Samoan music at home so that her young son would be familiar with hearing Samoan. Samoan music also provided a way for her to connect to her language and provide a platform to listen and practice Samoan pronunciation.

Participant 1 identified music as a form of comfort and connection. Listening to Samoan music first thing in the morning, often is the only time she would hear Samoan. Samoan 
music provided an avenue of hearing her heritage language but also connected participant 1 to her grandparents whom she was close with and only spoke Samoan.

The following excerpt is a conversation that followed in the focus group when discussing places in which participants most often heard Samoan being spoken.

\section{Excerpt 5}

1. Participant 11: Music, like I don't realise it, until like right now. If we

2. listen to music like on a daily basiss, you go through random music, most

3. of the time we end up in like Samoan music or Samoan jams or like

4. remixed stuff. And that's like the most we hear Samoan.

5. Participant 10: You might only pick up three sentences out of the whole

6. song, but you'll still belt out that song like you know it. Like it's speaking

7. to your soul kind of thing.

8. Participant 12: My parents have like the Samoa observer or the Samoa

9. times at home. $\left({ }^{*}\right)$ My dad reads them all the time, and because my dad 10.likes to put newspapers on the dining, when I'm by myself I pick one up 11.and I read out loud and kind of practice.

12.Participant 7: Samoan radio, you would know when it's on when like the 13.I think it was the Cook Islands they just finished [...] and then the 14.opening (sings) SAMOA (group laughter). I remember when I was little, I 15.used to memorize the whole speech he (radio announcer) does before 16.the Samoan news. Like there were certain words that they used. I

17.remember Grandma always let me turn it on, I was always the one 18.turning on the radio.

Music also provides rhythm, melody, harmonies and at times rhymes - making it easier to remember lyrics. The memorisation of lyrics is also the learning of Samoan words, terms and meanings that they would normally not have access to in everyday life settings.

The fond memories of time spent with her grandmother that participant 7 shares in lines 12 -18 highlights the importance of space and place of learning and practicing Samoan. 
4.2 Role of Grandparents, family and heritage in supporting language maintenance and cultural connection

Key factors that contributed toward the maintenance of Samoan for Samoan speaking participants was the support of 'âiga constantly speaking Samoan to and around participants on a regular basis. Being raised within the same household as participants grandparents who often would only speak Samoan to their grandchildren and participating in fa'a Samoa events that strengthened their knowledge and confidence to be present and participate in fa'alavelave's.

Genealogy, 'āiga, and cultural connection were key areas that were identified by all participants, that contributes to maintenance and use of Samoan. The sudden absence or loss of grandparents or family members that encouraged daily use of Samoan weighed heavily on non - Samoan speaking participants. It was common to hear stories from NSSP of feeling disconnected to their sense of being Samoan when they experienced the loss of close family members who were seen as the keepers of fa'a Samoa within their 'ãiga.

\subsubsection{Samoan only speaking households}

All Samoan - speaking participants shared stories of being raised in Samoan only speaking households. This rule was enforced and supported by all family members including most significantly - Grandparents. Regular contact with extended family members and grandparents encouraged participants to use and maintain Samoan from an early age right through to the present.

In excerpt 6 participant 6 talks about her father's commitment to ensuring that his children were raised speaking their heritage language - Samoan. 


\section{Excerpt 6}

1 Participant 6: Both my parents spoke Samoan to us it was a must. Dad wanted us to learn

2 the language and he did not want us to lose that, hence why he made the rule $\left({ }^{*}\right)$ I mean

3 you spend what? About eight hours in a westernised schooling system (+). Once you step

4 into school then that is when you can speak English. When you come back home you speak

5 Samoan because that is the only language that he wants. I thank my parents for that rule, I

6 mean I love the language $(+)$. I guess at the time I did not because we stuttered a bit trying

7 to pronounce words and all that, home and Church helped with that [...]

Being raised in a Samoan speaking household in which all family members are able to speak and work hard to ensure the language is spoken and supported is a privilege combined of several factors.

In lines four to seven participant 6 points out the struggles of time constraints and challenges that many families face regarding time afforded to spend with one another and encourage the use of Samoan.

\subsubsection{Significant role Grandparents play}

The role of grandparents carries great importance towards the use and maintenance of Samoan for both speaking and non-Samoan speaking participants. Non-Samoan speaking participants in particular indicated no matter how limited their Samoan was, they would attempt to speak Samoan as a way of showing respect - this was not exclusive to just grandparents but also when in the presence of Samoan elders. The role of grandparents or elders held further importance as a vital form of connection to their gafa and agaifanua The active role of grandparents carries momentous weight as they provide a sense of connection to Samoa, language and culture, alongside a sense of belonging. This point is made when participant 3 articulates his desire to be able to speak Samoan in the following excerpt. 


\section{Excerpt 7}

1 Participant 3: I wish I could speak it (Samoan) and actively have people around me that 2 could speak it. It (Samoan) connects me to my [...] well my mum but also my Grandmother. 3 She's passed away now but it connects me back to Samoa.

The connection to Grandparents that was felt by majority of participants goes beyond a physical sense but also spiritual and relational level. This connection contributes to the use of Samoan language even when Samoan language skills are extremely limited. In lines two and three, the desire to be connected to his grandmother, but also Samoa as a whole implies the role of connection that his grandmother provides for him.

Presence of grandparents and elders is a luxury that may not always be plausible for families in Aotearoa as finance, resources and time may be restricted. However, the presence of grandparents / elders carries great meaning and connection.

In the next excerpt, participant 5 shares a beautiful story of her grandfather teaching her to read the Bible in Samoan. Emphasising the important role as teachers many grandparents carry.

\section{Excerpt 8}

1. Participant 5: He taught all of us how to read the Bible and things like

2. that. So now we can read anything like anything. It doesn't even have

3. to a be a Bible it could be like a Samoan newspaper [...] (*) It would

4. be really random. [!] It would always be so random he'd just be in the

5. kitchen and he'd be like "hey do you want a Tea? Come and have a

6. Tea in here $\left({ }^{*}\right)$. He created a really good environment for us it wasn't

7. forced. I think that is another good thing is that it wasn't forced and

8. because he was [...] I don't know he was always really soft spoken

9. that you didn't want to do be $\left({ }^{*}\right)$ "oh nah I don't want to do that". No, 10.we were going to do it. But nothing was ever really forced. And

11. because we really loved our grandparents, we knew how important it 12.was for them. So [...] we were like "let's do it" (!) 
Times of learning how to read Samoan rooted in quality time, located in a calm loving space. Not feeling her lessons were forced with her Papa indicates absence of anxiety or uncertainty. Enjoying both the time spent and lesson learnt, for majority of the participants grandparents were a life force of their language, culture and heritage.

\subsubsection{Relationship between loss of Grandparents and disconnection}

Carrying on the theme of grandparents and the significant influence they hold over participants, loss of grandparents expectedly held detrimental consequences for few participants whose grandparents had passed on. Feelings of sudden disconnection to agaifanua, gafa and gagana was felt by participant 1 when her Mama and Papa (Grandparents) passed away. Placing great emphasis on her feelings of inadequacy at times. For most participant's grandparents main form of communication was Samoan, for several participants it was the only time they were spoken to or heard Samoan within their household.

Excerpt 9 participant 1articulates the devastation she felt when her grandparents passed away and the sudden realisation her grandparents played a pivotal role in her connection to Samoa.

\section{Excerpt 9}

1. Participant 1: I guess because when my grandparents were alive. I didn't

2. feel the need to have know anything, they were the matriarchs of our

3. family. If we went anywhere or did anything, they did it you know? So

4. why did I need to know it? And so, once they passed away that was

5. when everyone kind of goes their separate ways $\left({ }^{*}\right)$ and then $\left({ }^{*}\right)$ you just

6. feel [...] alone. You don't have that link anymore because my mum never

7. speaks Samoan only when she tells us off $\left({ }^{*}\right)$. I didn't long to be

8. connected to my Samoan side you know sort of heritage at the same

9. time. It never happened until my grandparents passed away. That's

10.when I felt like this disconnectedness mostly because of the funerals and 11.everything was done in the Fa'a Samoa way and we weren't able to help 12.or do anything because we didn't know how to 
The realisation too late that her connection to her language and culture was largely grounded in her relationship with her grandparents, caused great distress as indicated in lines five and six. Loss of hearing Samoan being spoken contributed to the feeling of disconnection discussed in lines ten, reiterating the point that grandparents were often the only speakers of Samoan within the home.

For many, grandparents lead the charge in regard to cultural rituals and customs, carrying deep understanding and knowledge of why and how protocols, customs and rituals should be carried out. The passing of grandparents can mean a loss of access to this knowledge.

The allusion of feeling insignificant was heightened during the funeral times, as reliance on grandparents for cultural knowledge and guidance was suddenly absent. The emphasis placed on the word "anything" in lines twelve reinforces the disconnect of belonging and role within the family and culture.

\subsubsection{Roles and responsibilities of eldest siblings}

Due to the change in structure, size and access to family support result of adoption of New Zealand context. Additional roles and responsibilities of elder/eldest siblings increased.

Two participants identified their roles and responsibilities as eldest siblings required both maintenances, use and retention of Samoan language and culture.

Participant 6 shares her role as eldest of six and how this contributes to her learning and continual use of Samoan in the excerpt below.

\section{Excerpt 10}

1. Participant 6: So, I mean there are certain things that me and my older

2. sister wished that she (younger sister) knew. [...] And she understood. I

3. think in her in her own way she decided not to take the language and

4. the culture. I mean she understands the culture side of things and

5. understands the language. But she chose at a certain point to stop

6. knowing those certain things. But she did make a comment, "oh I wish I

7. knew more". And then we would be like "oh we wish you would have

8. paid attention". I mean we all went to the same event not one was

9. separated. But it was at a certain point she stopped. Knowing or having 
10.that cycle of knowing the language and culture. I guess for her it was just

11.too much in a way. Whereas myself and my oldest sister. We had to,

12.because we're the older ones. Yes. We had to do this and that we had to

13. be by dad's side. Because he was a high chief and so everything, we

14. needed to know, you have to be placed here. You have to listen out for

15.the keyword and then walk and take the ie toga* for the si'i* and all

16.that. But it's totally different. It's the same for myself and my sister but

17.from my perception is that I took it up more than my other sisters. $\left({ }^{*}\right)$

18.And it's different for me and my sister as opposed to like my younger

19.siblings.

Participant 6 implies a sense of choice versus necessity in regard to language and cultural knowledge retention In lines 9 and 12. Putting forth the idea that although you may be raised in Samoan speaking household does not necessarily mean one will maintain the language.

\subsubsection{Role of the Church}

The role of Ekalesia Faapotopotoga Kerisiano Samoa (EFKS) played a critical role in the maintenance and use of Samoan for Samoan speaking participants. By chance all Samoan speaking participants grew up in the (EFKS) church. All services and songs were in Samoan and there was great commitment to the preservation of Samoan language and culture.

Participant 5 talked about the elders in her Church taking turns once a month to teach a class of aganu'u Samoa, focusing on Samoan ritual and custom, in effort to pass onto the youth knowledge of Samoan rituals faalavelave and their roles within these customs.

The excerpt below outlines the significant role the Church plays in regard to continuing to keep the language and culture alive 


\section{Excerpt 11}

1. Participant 2: They (EFKS) have a very strong structure and I guess the

2. structure that they've kept, almost like for as long as I've known them.

3. Nothing's really changed with EFKS. $\left({ }^{*}\right)$ Dates back to even LMS $\left({ }^{*}\right)$ way

4. back in the days when the missionaries came in, they introduced

5. churches to Samoa. But I think one of the key values was $(+)$ just

6. ensuring that it belongs to Samoa [...] that it [...] almost like part of the

7. identity of Samoa as well

Lines two to five, participant 2 talks about how little the church has changed, implying his EFKS church still sits within a traditional realm of Samoa. Highlighting the interconnectedness of church and the Samoan identity in line five. Indicating that the church is also a marker of his identity as the Church makes great effort to "belong to Samoa".

\subsection{O le alofa ma le puipui - Love and protection}

A prominent theme throughout the findings was the theme of love and protection grounded in the notion of the want for a "better life". The motivation behind the first generation to migrate in search for a "better life" was both directly and indirectly implied by all participants. To explore this finding, identifying the three key acts of love and protection must occur.

The first is the act of love of the first generation migrating from Samoa to Aotearoa New Zealand in search of a better life for their future generations. The notion of a "better life" was steeped in colonial values, remnant of the New Zealand administration and colonisation of Samoa during 1800-1900.

The second is the act of adopting the New Zealand context, and English language not necessarily by choice but out of necessity, highlighted through the realisation that English was a language of privilege. From this adoption, boundaries of relationships that once coexisted with one another to reinforce the vā were erased for many families. Thus, resulting at times in vulnerabilities within families to become exposed or exacerbated. 
The third act of love is the present (second) generation recognising the gifts of the Samoan language and cultures. Yearning to find belonging in both language and culture through access to language and culture. This second generation is in the process of realising a new definition of what "a better life" entails.

\subsubsection{First act of love - first generation migration}

Speaking English was the outcome of necessity not choice, the English language was rooted in privilege that was the gateway to success and better opportunities for the next generation to come. A majority of spaces if not all, besides the home the Samoan first generation entered were English only speaking spaces (see excerpt 7). Restraints of finances, time and family support contributed to the notion of English taking precedence over Samoan.

The following excerpts illustrate the challenges families faced raising their families in a foreign land

\section{Excerpt 12}

1. Participant 11: I'd say it's the same for me. [...] I don't know if language was

2. valued because it just wasn't at the forefront of everything, we did. [...] So, I

3. think English was just like a default easy way of going about life. As I grew up

4. it wasn't until like if we if we were in like an environment where there were

5. other Samoan people my mom would be like only speaking to me in Samoan

6. and it would be like for her to.... (I reckon) for her to make it clear to everyone

7. that her daughter can speak Samoan. Or can at least understand. And then

8. I'd be like "Oh man. I can only respond in English" but like you know like at

9. least I could comprehend. And I think it was more for her to know that her 10. children are Samoan.

In lines two to three "English was just like a default easy way of going about life" highlights the difficulties that first generation Samoans would have faced trying to speak and maintain their heritage language in a land that made it difficult for them to do so. The challenges that 
surrounded speaking Samoan, reinforced the idea that English was both accessible and language of great privilege.

Participant 11 talks of uncertainty of value placement on Samoan within the home. This idea is contradicted in lines one to three, as her mother makes a point of speaking Samoan when in the presence of other Samoans. The space in which they were in, was a safe space that was both socially appropriate and culturally accepting. Her mother making a point to speak Samoan in front of other Samoans also indicates a feeling of pride that is instilled with speaking and knowing the language. In lines eight to ten the idea of language being a marker for identity is reinforced.

\section{Excerpt 13}

1. Participant 4: I think she just tried to speak to us about it (Samoan culture)

2. [...] Well you use that language at home. But it wasn't her main focus to keep

3. the culture alive I guess [...] I think at the time that we're growing up her main

4. focus was to work to survive.

Participant 4 brings attention to the reality of needing to "survive" in an unfamiliar land and context. Large responsibility towards not only the nuclearized family living in Aotearoa but also the extended family living back home in Samoa is a heavy load that is carried by two or at times one parent. In the search for a better life, the commitment and obligation to 'āiga that was once shared amongst the many members of the family is now carried by one or two people directly. The impact of this "surviving" reinforces the precedence of English over Samoan. English becomes the "default easy" as all interactions outside the home are done in that language.

\subsubsection{Second act of love - Fractures of relationships}

The values that are highlighted by participants in section 4.2.2.2 correlate with the challenge of navigating both a Samoan worldview and Palagi way living (4.3.1.1) The frustrations essentially were premised in the difficulty of living within a Palagi everyday context which favours individualism over collectiveness. Secularism over spirituality and the nuclear family over the wider extended family. Values that are essentially the opposite of the Samoan values (see 4.2.2.2) that dictated one's ethics and morals of living life. 
The combination of pressures to adopt these values alongside the reality of the New Zealand context exposed vulnerabilities within families that created harmful situations at times, disrupting the Samoan boundaries that once co-existed to ensure harmony and balance.

In the next excerpt two participants from the focus group share, reflect and respond to one another regarding removal of one'self from the Samoan language.

\section{Excerpt 14}

1. Participant 7 : So, for me it was mainly whenever we were together with our

2. family. Her mother my dad's side of the family where I didn't [...] it got to the

3. point where I didn't really want to speak it at all. I have like a deep resentment

4. for my dad's family [...]. $\left({ }^{*}\right)$ And that was the biggest kind of thing for me [!] oh

5. well I think that made me stop learning the language because I was just like

6. "what's the point" in terms of like OK if I learned the language. I must

7. conversate with these people [!] A lot of that was just from my personal like

8. just personal trauma with my own family our own family experiences.

9. Participant 11: Thanks for bringing that up because it actually makes me see

10. a perspective that I think for my mum I think that was a similar experience

11. that prevents her from engaging with her Samoan identity as well as her

12. family. But the consequence of that is that it was, being Samoan wasn't alive

13. like it wasn't like a spirit that was [...] that we then inherited. So, because [...]

14. She didn't engage in her Samoaness we or she resented it or $\left(^{*}\right)$ it was like

15. she resisted it. We didn't get the opportunity and because we didn't it was

16. more "oh we have to do it for ourselves". [...] So that's where making friends

17. who had similar values $\left({ }^{*}\right)$, we still had values and we still had the values but

18. with the essence of being Samoan it was lost.

Protecting the next generation from the hurt that occurred as fracture of these relationships, at times resulted in parents choosing to disassociate themselves and their children from the Samoan language, culture and family. Resulting in the shift of Samoan language within the space of one generation. As participant 7 shares her frustrations, participant 11 comes to better understand her mother's choice and the reasoning behind her actions. Finding 
different avenues of connection to culture and language pointed out in lines 16 to 18 , was a way of reclaiming one's culture and connection back.

\subsubsection{Third act of love - A new defining of "a better life"}

The third act of love, the act of love and protection of the present (second) generation. The dreaming of a new "better life" as a result of the crucial need to stay connected and feel a sense of belonging to the language and culture.

All participants expressed a strong desire for their children, nieces and nephews to be raised speaking Samoan, or to be rooted in their Samoan culture and language. The fear that their future generations would also endure the same feelings of disconnection, inadequacy and displacement motivated participants to persist in strengthening their confidence and knowledge of the Samoan language and culture.

In the next excerpt we see participant 11 talk about taking charge and finding a way to ensure that her children do not experience the same feelings of disconnection she endured.

\section{Excerpt 15}

1. Participant 11: When I look at things like taking on a Samoan language

2. class, hopefully this a big component that can link some of these

3. fragmented pieces together. And so that's why I don't have an excuse,

4. I'm an adult I have to take charge with what I can. And even if I think my

5. upbringing was very unfortunate in the sense that I lost my language and

6. language wasn't prominent and I didn't have as many opportunities as

7. everybody else. I didn't go to a Samoan church; I didn't get that

8. opportunity. Now I have to do it for myself and hopefully instil the

9. values in my own children that are strong enough for them to do it for 10.themselves.

The notion of creating a "new better life" is not completely re-defined by the present and third generation. It comes from the idea that "a better life" cannot be attained without the inclusion of one's heritage language and connection to culture. 


\subsection{Relationship between wellbeing and language maintenance/shift}

Both shift and maintenance of Samoan language was found to have a direct correlation between one's sense of wellbeing. Understanding participants own ideas and definitions of wellbeing was core to understanding the impact of shift or maintenance of Samoan language. Participants had varying understandings and definitions of wellbeing. However, the general premise of wellbeing was that it was to be mentally, spiritually, physically strong healthy and resilient. The following excerpt comes from participant 7 sharing her understanding of what wellbeing means.

\section{Excerpt 16}

1. Participant 7: I think at the end of the day wellbeing for me is definitely

2. more emotional and spiritual well-being. If something is wrong with the

3. mental and emotions like even your physical health is affected. If your

4. mind and your heart and your spirit is not in sync, then everything else

5. fails everything is like a butterfly effect. If one is not right, then whatever

6. you did affects this person it effects that person you know? It's all

7. connected. There's not only a language like language and culture it's

8. intertwined. It's like without the hardship we can't bear any fruit. And

9. when we look at our elders like you know your mom and you have your

10. mother in law and you see that they went through and they've became

11. such great such great women. $\left({ }^{*}\right)$ Even though they went through all of it

12. but it's like you know at the end, there's something to aspire to you know

13. that there's something good that comes out of all this bad. And so, for

14. wellbeing it's definitely more emotional. Spiritual.

\subsubsection{Samoan language is relational and spiritual}

As participants talked about their own understandings and perceptions of wellbeing. The theme of Samoan also being a relational language was prominent throughout all the discussions. Emphasised by the notion of only understanding Samoan when spoken to by close family members.

The following excerpt is an example of this from participant 1. 


\section{Excerpt 17}

1. Participant 1: And it's real weird too because I can understand anything

2. that my grandparents say in Samoan anything at all [!]. I got to the point

3. I could understand anything. But when somebody asked else speaks

4. Samoan to me, they could say the same thing as my grandparents but

5. sometimes I can't understand. I'm like "huh" and then they have to say a

6. few times. But anything my grandparents said I could understand.

This excerpt reinforces the connection between Grandparents and grandchildren and the relational space that is held within the Samoan language.

\subsubsection{A state of two minds}

Being raised with Samoan values that dictated one's choices, actions and way of being essentially, was often questioned when confronted by situations that either clashed with said values, understandings of a New Zealand context and Samoan worldview requiring explanation. The following excerpt highlights this challenge through the conversation between two participants in the focus group.

\section{Excerpt 18}

1. Participant 10: That is like my biggest battle (+). Because am I

2. thinking with my Palagi brain is that why I am not understanding? (+)

3. And then me and my partner at the time would get into arguments

4. because l'd question something. But for him it was so straight forward,

5. and he'd be like "how do you not understand that"? And then I'm like

6. am I thinking with a feminism slash NZ raised brain?

7. Participant 9: I second that actually it's kind of like determines which

8. road you're going to go down. Do I go down the road of Palagi way of

9. things or Samoan ways of things? Like me and my partner argue not 10.often. I'd say it's just more. If he thinks something's right, if it's the Fa'a 11.Samoa way but I'm thinking with my palagi brain

A task that creates internal conflict, is the attempt to understand from both a New Zealand context and Samoan worldview. The question of thinking with a feminist mind-set, highlights 
the unspoken understandings of Samoan ideology and concepts that can be misinterpreted or misunderstood through the attempt at Englishing Samoan concepts, worldviews and understandings.

\subsubsection{The presence of Samoan language}

The presence of Samoan language was described by participants to promote one's understanding of knowing their place and provide a sense of grounding. Language was seen to be a bridge to the past and future, great pride surrounded the idea of being able to speak Samoan but also understanding the value this adds to one's life.

In the next excerpt participant 2 shares his view on the presence of Samoan language and strength he gains from it.

\section{Excerpt 19}

1. Participant 2: Being able to speak Samoan has huge advantages. It is a

2. connection between ourselves and our elders. I use the term fa'aloalo.

3. One thing my uncle always said to me was "you become a very snotty

4. person when you speak to me in English and you're very disrespectful.

5. One of his questions was "who do you think you are?" I never

6. understood it until you know, he said "it's the way sit, the way you walk,

7. the way you dress. The way you speak. It tells who you are. You talked to

8. me in English are you telling me you're a Palagi? So, you know, it's our

9. connection, the way we speak to our elders. We are fortunate, we're 10.very lucky to be able to speak two languages. But at the end od the day, 11.Samoan will always be my first.

Through both presence and ability to speak Samoan, a sense of connection, reminder of worth and pride is instilled in participant 2 on a daily basis. Identifying that the Samoan language moves beyond the present opening a space that carries one'self between the past, present and future. 


\subsubsection{Importance of participation}

The critical need to ensure teaching of Samoan rituals and customs is passed from one generation to the next was reiterated many times over throughout discussions. Either by explicitly talking about the frustration of not being taught what one's role is during faalavelave or implicitly when participants would share stories of frustration or feelings of shame when faced with faalavelave. The lack of knowledge of both role and purpose of such significant events meant for many participants, avoidance of faalavelave or Samoan functions via staying in the kitchen relying on their parents to be take part and be present was common.

Excerpt 20 underscores the need for parents or elder family members to teach or include the next generation when planning or participating in faalavelave to ensure learning takes place for the future.

\section{Excerpt 20}

1. Participant 10: Our family it's handled behind the scenes I feel like. We

2. don't have much involvement My mom will send a group message and

3. we're like sweet I can do this much. Like my mum will ask how much we

4. can put in and there isn't a set amount or requirement of what is

5. acceptable. Mum just asks how much you can put in? That's sweet. Even

6. my brothers in Aus.

The handling of the faalavelave behind the scenes is beneficial in the short term, however learning of the processes, guidance of customs and rituals is not being passed down to the next generation.

\subsubsection{Impact of being ridiculed when trying to speak Samoan}

Fear of being laughed at or mocked when attempting to speak or struggling to understand Samoan was a common denominator amongst NNSP. Fear of being ridicule contributed immensely towards lack of confidence, and a sense of shame and inadequacy when in the presence of unfamiliar Samoans. This in turn created a sense of deterrence of speaking or associating with both Samoan language and peoples. 


\section{Excerpt 21}

1. Participant 4: Understanding $\left({ }^{*}\right)$ I don't know how you say it [...] in

2. depth in the language but it doesn't mean I would use it because

3. obviously, them two would mock me. So, I don't try and reply in any kind

4. of way and when I do, they mock me but there's been attempts where I

5. do try... but no.

6. Researcher: If they weren't so mocking [...] would you attempt?

7. Participant 4: Yes [...]

8. [...]

9. Participant 4: But sometimes if I try to figure out how to say something, 10.them two would be the ones that I can still rely on and be like "hey guys 11.can you translate this for me" and they would.

Line two reference to "them two" are participant 4 close friends. Indicating that due to their mockery at times she chooses not to try to reply in Samoan. Use of "obviously" suggests an expectation of being mocked or laughed at to occur. Expectation of mocking contributes to participant 4 insecurities of having to speak Samoan. The long pause between line five and line eight suggests deep thought for a moment, suggesting a sense of internal conflict. Acknowledgment of one of the many strengths of their relationships takes place in the final lines implying this statement was a new realisation.

\subsubsection{Role of humour as both resilience and connecting to culture}

The role of humour was raised several times over throughout both the one on one sessions and focus group discussion. Both ideas of humour acting as a form of connection, inclusiveness, resilience, and relationship building. Participants also identified humour as motivation to learn Samoan and felt encouraged making a point of learning Samoan through humorous banter. 


\section{Excerpt 22}

1. Participant 4: It was funny Sarah actually told me that Bob actually

2. didn't know how to speak Samoan. He $\left({ }^{*}\right)$ felt like majority of us he was

3. gutted that he couldn't speak to his own uncles or like laugh with them

4. in the way that they do with each other. So, he just hung out with them

5. a lot and tried to speak Samoan with them, and they would fault him on

6. whatever he's saying wrong. He would take it and then he would fix it.

7. And then over the years he actually picked up his language and then he

8. would he had to do his speech at his brother's wedding in Samoan.

\section{Excerpt 23}

1. Researcher: What helped you through the tough times?

2. Participant 4: It was humour. Yeah. Obviously, that's what I mean. Well-

3. being to me is being mentally strong because on a daily basis you're

4. fighting like your job that you don't like or because you're doing it for

5. your family, or you've got family stuff $\left({ }^{*}\right)$ that's going on. Got to $\left({ }^{*}\right)$ laugh

6. it off because you're so serious and so, deep in thought. That when

7. someone else is cracking jokes like haha (!) I forgot what my life was

8. really like.

Two points are raised in these excerpts. The role humour plays in regard to maintenance and reclaiming of Samoan language. The second is humour being seen a form of resilience that helped participant 4 get through challenging times. The distraction of humour prevents one from entering further into a deep sense of despair as stated in lines seventeen and eighteen "you're so serious and so deep in your own thoughts". 


\section{Chapter 5 Discussion}

\subsection{Discussion outline}

Detailed exploration of the key theme findings which answer the three research questions guiding the research and identifying the underlying embedment of the themes.

\section{$\underline{\text { Three research questions }}$}

1. How do second generation Samoans see language contributing to identity?

2. Where are second generation Samoans using and learning Samoan?

3. Is there a relationship between wellbeing and language shift or/ maintenance?

Theme 4.1 Lack of value placed on Samoan language in the education system highlights the interconnectedness of language, identity and culture; pointing out where Samoa language is not being spoken or taught; and lastly, identifying the shift of language and its impact on one's wellbeing.

The theme of recognising the lack of value placed on Samoan in mainstream educational context identified that language culture and identity are interconnected. The refusal to acknowledge or support Samoan language within the schools resulted in participants feeling they were not seen and their identity of being Samoan ignored or irrelevant. Schools were often seen as spaces that did not allow room for Samoan language (see excerpt 2).

Providing few Samoan language learning opportunities and little to no transitional bilingual support, resulted in participants seeking language maintenance and connection through other avenues. Through the seeking of different avenues to hear, practice or speak Samoan, a correlation between language shift and one's wellbeing was highlighted.

Participant 10 shared her frustration at the limited teaching of Samoan that was offered in her high school. This emphasised her own insecurities of her Samoan language ability. From this theme the notion of schools not having sufficient resources or skilled teachers to teach Samoan at a high standard equal to non-Pacific languages offered within high schools was raised (see excerpt 1 ).

This touched upon the lack of government's support for schools to support students in their learning and maintenance of their heritage languages. The governments education policies 
and vision signalled their limited valuing of heritage languages and can be seen through making Te Reo Māori an official language of Aotearoa New Zealand as late as 1987.

Through the government introduction of education policies including the "Language learner policy", Samoan language was shifted from a community language to a foreign language removing the government's responsibility ensuring they provided a space of Samoan language maintenance and retention (2012). Teaching and pursuit of Samoan language was now at the discretion of both the school and learners.

\subsubsection{Polynesian Club}

Theme 4.1.1.2 looked at the significant spaces the school Polynesian Club's opened up for participants. A space to gather, celebrate one's language and culture, and essentially a space to exist in a context that acknowledged and supported one's identity (see excerpt 4). A documentary by Radio New Zealand, (2019) looking at the role of Polynesian clubs, acknowledged the significant space that was provided to allow students to thrive in a context that valued their language, heritage, culture and skills.

Such involvement and the success of participation in the Polynesian festival was mainly due to the students' parents and families, with the intention to further foster their children's language and culture. In excerpt 15, participant 11 talks about finding different ways to connect to her culture through language. The Polynesian Club provided a form of connection and learning that not all second and third generation Samoans have access to.

The creation and sustainability of such spaces is a sign of strength, an example of resilience and hope for previous, current and the next generation of Samoan learners and leaders. A collective effort by families and students both past and present, in working hard to ensure Polynesian Club continues to exist for the next generation of learners.

A lack of access to Samoan language learning classes, resources or representation of Samoan teachers was expressed as contributing to participants feeling their identity, language and culture were not valued. This reiterated the interconnectedness of language culture and identity. 


\subsection{Role of family, genealogy and heritage}

Theme 4.2 identifies the significant roles family, genealogy and heritage plays in regard to the maintenance of Samoan language.

The interconnectedness between language, culture and identity was highlighted when examining the significant role family members played in regard to the maintenance of Samoan language and the connection they provide when language shift has occurred.

\subsubsection{Grandparents}

Tamasese \& Parsons (2019), describe the Pacific person to be understood as a "relational person". Identified by genealogical lineage and cultural connections through both maternal and paternal lines, connecting to the present generation, spirit of the world of ancestors and the lands in which they came from.

Grandparents played a significant role in one's relationship of identity and connection to their culture and heritage language. The role of family in regard to the maintenance and retention of Samoan is critical as highlighted in excerpt 8 . When language shift occurs within a household most participants talked about finding connection, or their identity being tied to their relationship with their Grandparents.

Through the relationship with their grandparents participants felt connected to their language, culture and grounded in their identity as seen in excerpt 7 . The sudden passing of Grandparents was described by participants as losing their connection to their culture, family, language and identity (see excerpt 9).

\subsubsection{Family support}

SSP (Samoan Speaking Participants) identified the language was most often used within the home and at church. This was enabled because of the family structure and support. This ensured the maintenance of Samoan language and directly contributed to their wellbeing as seen in excerpt 18 .

SSP talked about their home being a Samoan-only speaking zone encouraging the daily use of Samoan. It was noted that all SSP came from two parent Samoan households, presence and quality time with parents was crucial to the sustainability of the Samoan only speaking rule (see excerpt 6 ) 
Maintenance of Samoan was supported through the regular family gatherings and contact. Encouraging the use and passing on of Samoan language and strengthening of family relationships as seen in excerpt (18). Davis and Starks, (2004) discovered that living within the same suburbs or in close proximity of wider family members contributed to the strengthening and maintenance of Samoan language. This was also the case for Samoan speaking participants.

While the role of Grandparents was significant for participants not each household was able to house three generations of family members. The physical restraints of space within Housing New Zealand homes and income restrictions limited the opportunities of three generations of families to live under one roof. Thus, limiting the opportunities and availability of time and energy that could go into ensuring maintenance of Samoan language within families (see excerpt 13).

Participant 7 highlights the effort that went into ensuring the Samoan language was spoken within the home in the following excerpt

1. I think it was just the norm. When I was younger, I did not realise how

2. much work my parents all my grandparents put into making sure that

3. they always spoke Samoan. I just thought it was normal.

\subsubsection{Sense of belonging that language provides}

One of the biggest assumptions that I noted was shared amongst many of the NSSP (nonSamoan speaking participants) was the idea that when one is able to speak Samoan that person immediately is knowledgeable in the Samoan culture - to the extent that knowledge of meaning and logic behind customs was well known. Lack of knowing of how one carries out tasks and responsibilities, and the understanding, meaning and significance of Samoan customs and rituals was a place in which much insecurity stemmed from for non-Samoan speaking participants (see example 9).

Ete (2004), talks about never finding a true place of belonging due to the constant back and forth between Samoan and New Zealand worlds. Participants 2, 5 6, dispute this notion. All three participants were born and raised in Aotearoa. They were raised speaking and living the Samoan language and culture and were grounded their belonging within their 'āiga, Churches and communities. 
What I look to emphasise here is that although they are able to speak Samoan, they also understand their responsibility and the level of commitment that is required to ensure the survival of their language and culture, increasing the wealth and health of their culture and language for their future generations to inherit. This was and continues to be demonstrated through their presence, leadership and active participation within their 'āiga, fa'alavelave, Church and community.

\subsubsection{Role of Churches}

Churches have been described as cultural hubs for migrant families (Malaeulu, 2017) providing a network of support and comfort, essentially a home away from home.

Participant 1 talked about her Papa being the first point of call for families within their parish that had just migrated to Aotearoa. He would organise housing and employment, assisting in any way he could to help families settle into Wellington. This narrative demonstrated the significant role Churches can contribute to newly migrant families and it is clear the second and third generation have reaped the benefits of the hard work and efforts Pacific churches and communities have put into ensuring Pacific families were settled and well supported.

All SSP were raised and are still active in Samoan churches. Theses participants credited the efforts of their Churches in ensuring the Samoan language was maintained as seen in excerpt 11.

The assumption that second and third generation Samoans still attend or grow up in Samoan churches cannot assumption no longer holds weight. NSSP identified they did not attend Samoan speaking churches. The "home away from home" (Malaeulu, 2017) concept may not be applicable to the second and third generation born and raised in Aotearoa.

A question we are left pondering then is, how can we emulate a Church environment that supports the maintenance and use of Samoan on a regular and continuous basis for NSSP who do not attend Church? 


\section{$5.3 \underline{\text { O le Alofa }}$}

The third key finding of the research was the act of love and protection that motivated the linguistic choices of the first, second and sometimes, third generation. Understanding this theme was broken into three sub-categories to best explore and understand the embedment of the three acts of love.

The third act of love - the redefining of a "better life" is born out of the realisation that the notion of what a good life consists of cannot exist without the inclusion and interconnectedness of language, culture and identity. Answering the first research question - second-generation view language and culture as part of their identity.

Majority of NSSP came from English speaking households. Samoan was often used or heard at the participants own discretion, such as listening to Samoan music (see excerpt 5) or reading Samoan newspapers (see 5). Reasons as to why households become English speaking or where a language shift has occurred within two generations will be discussed in further detail first act of love.

\subsubsection{First act of love:}

The first act of love is grounded in the notion of a want for a better life - better opportunities for education, employment and prospects of a more successful future (Salesa, 2018). The pursuit of a better life was not an individual but a collective decision. Migrating to New Zealand meant financial support for family back home in Samoa, and the opportunity to provide the foundations for a more prosperous future for the following generations.

There was a big push by the New Zealand government for Pacific migration to cater to the shortage of workers required to meet the needs of the New Zealand labour force (Salesa, 2018). Migrating to New Zealand required many sacrifices for Pacific peoples. Language, values, culture and knowledge rooted in the collective way of living was made to feel it had no place in a New Zealand context (Hunkin, 2012) see excerpts (4 and 2 lines 14 -16)

Government assimilation, language and immigration policies are some of many examples which promoted English to be viewed as a language of success, contributing to what Hunkin (2012), would call the brainwashing of parents to convince them their children would not need their heritage language. 
Thus, leading to Samoan to be viewed as a language of deficit (Samu et al, 2019 as cited in Hunkin, 2012) and English as a necessary tool instrumental to the building of a better life. Excerpt 11 demonstrates the impact of this as the participant refers to English as a "easy default". Spaces that were opened and made room for Samoan language were often provided by family members (see excerpt 5 lines $12-18$ ).

The strength and resilience of the Samoan peoples is highlighted through the community initiatives for Samoan language retention and maintenance such as ā'oga 'āmata (Samoan preschool) and Samoan media - Radio PI fighting to ensure the Samoan language survived and would thrive for future generations (Hunkin, 2012).

\subsubsection{Fractures of relationships:}

I was once told by my uncle that language embodies the values of one's culture, I didn't quite understand what he meant at the time until I listened to participant 2 share a story about a lesson he learnt from his own uncle (see excerpt 18). He was told that when speaking English, he became a"snotty person", and when speaking English to his uncle he was stating that he was a "Palagi". The point I want to highlight is language dictates how one chooses to identify, behave and hold themselves. So, when a language shifts or is repressed, so too are the values that once guided the actions and behaviour of a peoples.

Values that reinforced boundaries guiding expectations of behaviour can be difficult to navigate in a western context as participants expressed (see excerpt17). The added stresses Samoan families faced migrating to Aotearoa New Zealand such as nuclearization of families, resulting in limited family support and carrying of financial burden exacerbated vulnerabilities within households that once would have been supported by the wider 'âiga and village.

At times these vulnerabilities' lead to hurt occurring within households, and for some in order to move past and not allow said hurt to occur again was to disassociate themselves and their children from the Samoan language and culture.

The disassociation was born out of love and protection, wanting to ensure the same hurt does not occur. Now as adults, participants identified they had struggled with not knowing their language, culture and family (see excerpt 15), when parents chose to raise them away 
from their culture and language in a bid to protect them but they now yearned to find connection and meaning within their language, culture and 'âiga.

Sharing of narratives around the choice to move away from one's language and culture in the focus group helped participant 11 to understand her own mother's choices and situation from a perspective she had never considered (see excerpt 14).

Parents wanted the best for their children and wanted to provide a "better life" or at least provide the tools that would allow the second generation to attain this idea of a "better life". From the previous section and literature review it is clear, English was deemed to be a language that provided opportunity and took precedence over heritage languages.

An act of love once again, wanting to provide the best for one's children by ensuring their first tongue was the language that offered promise for a better future, less struggle and protection from the struggles that first generation may have had to face.

\subsection{3 $\underline{\text { Re-defining a better life }}$}

The third act of love, the love of the present generation wanting to reclaim and reconnect to and through culture and language arises from a place of decolonisation, realisation and privilege.

An act of decolonisation in pursuit to reclaim a language and culture that one was deprived of due to the deeply rooted consequences of colonisation.

Realisation that living in a world without one's language or connection to language creates an imbalance of wellbeing.

Privilege in the sense that the second generation are in a position to view and understand the impact of the loss of and look to ways of reclamation of language, whilst reaping the benefits of the hard work, sacrifices made, and the resilience of the first generation, allowing one to be in a space of re-negotiation of what a better life may entail for past, present and future generations.

Anae (2001) argued that assertion of belonging to a culture or ethnic identity does not require competency in the language of said ethnic identity. Whilst I agree with this to some degree, the findings indicated otherwise. Participants identified language as being spiritual, relational and meaningful (see excerpt 16). The basis of what surrounded many of the 
struggles participants shared, was the lack of knowing expressions, understandings and meanings that best articulated the Samoan nuances which Hunkin (2012) argued was the essence of "Samoan-ness". It becomes redundant when inability to convey meaning and nuances of Samoan expressions occur.

This is not to say the instinct of Samoan-ness is lost.

Participants often talked about having "common-sense", common-sense in a Samoan context, common sense in knowing what one must do and how they should act and common-sense that when asked to describe what they meant was often met with answers such as "I know it in my head. I know what is right or wrong, I just don't know how to explain or word it" (personal communications).

It was this instinct that brought participants to the point of realising that it was not possible to separate language and culture from identity.

A sense of belonging is rooted in knowing of one's role and place, within both the immediate and wider 'āiga. Informing a sense of belonging as excerpt 9 demonstrates, not knowing of one's place can lead to a sense of disconnection. Knowledge of the practicalities behind rituals and customs of fa'a Samoa provides guidance within a Samoan context and informs belonging.

Wholeness is informed in the idea that language culture and identity cannot be separated. Excerpt 16 talked about the butterfly effect when language shift occurs.

In excerpt 15 we see participant 11 talk about taking control of the situation. In lines four to seven, she acknowledges the need to "take charge" recognising that although she may not have had the same opportunities as other Samoans, it was now up to her to find way to reconnect or instil values in her own children.

The entirety of the desire to redefine what constitutes a better life is enveloped in alofa. 


\subsection{Relationship between wellbeing and language maintenance/shift}

Wellbeing

Depending on context and locality of person, wellbeing can be defined and interpreted in different ways. Diener \& Suh (1977) viewed wellbeing to refer to one's pleasant and unpleasant moods and emotions and satisfaction of life (p.200). Whereas Tamasese \& Parsons (2019) conceptually define wellbeing as a concept that encompasses a life or collective lives, sustained by relationships. A life with blessings, lived in abundance spiritually, mentally and physically (p.58).

Excerpt 16 is a representation of the many definitions participants provided when putting their own words and understandings to what wellbeing means for them. In excerpt 16 participant 7 talks about the spiritual, physical and emotional elements of wellbeing. In line with theme 4.3.1 that language is relational and spiritual.

At times participants were at a loss for words or meanings to articulate the spiritual nature Samoan language encompassed, however, it was both directly and indirectly implied the instinct and presence of spirituality that encompasses language and contributes to balance of wellbeing was present.

Matching the understanding of Pacific wellbeing provided by Tamasese \& Parsons (2019) Pacific wellbeing is both spiritual and material. Spirituality and materiality for Pacific peoples is therefore also inseparable, integrated and interconnected (p.49).

\subsubsection{The four core relationships}

Tamasese \& Parsons (2019) identified four key relationships that must be in balance with one another to achieve harmony and state of wellbeing. These include the Pacific person in relationship with Atua, the environment, relationships with ancestors, culture, language and heritage Pacific person in relationship with others (p.40).

This reveals how a disruption of one relationship places strain upon the others. It was evident for both SPP and NSPP Samoan language played a profound role in the way in which they saw themselves and viewed their own relationships with 'āiga, ancestors, spirituality and culture. 
Excerpts 15, 16, and 17 demonstrate how one's wellbeing is impacted when language shift occurs or is present. In sharing their stories of feeling grounded, and language being a source of strength

SSP shared stories of feeling grounded, of language being a source of strength and feeling intrinsically interconnected with their identity. A shift of Samoan language was described by NSSP as feeling inadequate or unsure of identity, belonging or place within both the New Zealand and Samoan context.

Samoan language shift impacted one's confidence, sense of belonging, identity and heightened feelings of insecurity of language learning skills. However, it was noted participants also found alternative ways to stay connected and grounded in their culture and language. The desire to reconnect and learn Samoan was expressed by all NNSP. 


\section{Chapter 6 Conclusion}

\section{$\underline{6.1 \text { Implications }}$}

\subsection{1 $\underline{\text { Choice of methodology }}$}

Through the implication of trying to use Talanoa as a research method, O le Filiga le Afa was born. A culturally derived Samoan research method appropriate to the context of the locality of the study. When carrying out the research process, I found the use of Talanoa as a guiding research method too broad and open to interpretation.

During a time of discussion and reflection with family elders on the topic of Talanoa and my concerns with the methodology. I visualised my great-grandmother making Afa. Immediately I likened the process as a metaphor to the research stages that were carried out.

As I talked with my family about the process of creating Afa it became more apparent the $\mathrm{O}$ le Filiga le Afa method was not only culturally fitting, but embodied guiding principles that as a result ensured the depth of respect for the lives lived and linguistic choices enforced as a consequence of the historical linguistic relationship between Samoa and New Zealand.

A difficult journey in the process of trying to make sense of best method to follow. However, from this struggle came $\mathrm{O}$ le Filiga le Afa method. Had I rushed to complete this project by the first initial due date I may not have been guided to create such a process. Reiterating the importance of not responding in haste and rush but allowing a process of thought to develop and be led by the elements interwoven throughout the procedure.

\subsubsection{Defining a new research process}

The challenge of using a Samoan traditional ritual or process as a metaphorical research process is the expectation to anglicise each Samoan term, stage or process. Just as the Afa process is not rushed, carefully calculated and thought out so too should be the need to place English terminology alongside Samoan terminology. As pointed by my elders each process has its own Samoan name, and with each name comes its own beauty and meanings. To anglicise this process in a quick manner without great care or thought can lead to the loss of this beauty and foresight as everyday English words can take away the collective and spiritual nature of the work itself. 


\subsubsection{Insider status}

Implications that may have arisen was the familiarity I had with participants. Fear of critique, judgement or exposing of one's family may have held back participants from sharing narratives and experiences that may have been relevant to the study.

\subsubsection{Gender imbalance}

The gender imbalance within the study was due to difficulties in securing times for data collection during the Christmas summer break. Although the aim was to have an equal balanced ratio of woman and men it was not possible. An implication of this is the narratives and experiences shared and were representative of Samoan second generation Woman. If I were to continue further study a balanced ratio of both woman and men would provide additional insight and understanding.

\section{$\underline{6.2 \text { Recommendations }}$}

\subsubsection{Policy development}

The implementation of a coherent and comprehensive Aotearoa New Zealand Languages Policy as identified in Aoteareo: Speaking for Ourselves (Waite,1994a).

\subsubsection{Education policies}

Forming of new education policies that are inclusive of and supportive of schools to ensure they provide and are well resourced to support heritage languages within their schools.

Funding for professional development of Samoan language teachers and provision of resources to support teaching and learning in the classroom and at home.

Access and funding for professional development and training opportunities for Pacific language nests teachers in Aoga amaata in-centre training.

Paid opportunities for parents or family members to be involved in teaching heritage languages in the schools.

Requirement for school boards to be reflected of their school communities.

Funding of Pacific based language resources for use in centres and schools 


\subsubsection{Transition to school first language policy}

All schools to have a policy to support children transitioning from language nests to schools to ensure they receive appropriate support for their first year of school.

\subsubsection{Housing}

Continued funding for Pacific homeownership. Housing policies that are catered to moving Pacific families out of renting and into home ownership. Schemes to allow access of Kiwisaver for families to extend their family homes as required to cater for their intergenerational family needs. Home ownership means families are not dictated by the rules set by the landlord or housing New Zealand. It also allows for families to renovate their homes to best suit the needs of their family, allowing for the possibility of intergenerational living to occur.

\subsubsection{Churches}

Working with Church leaders to foster and engage Samoan language learning opportunities both within and outside their parishes.

\subsubsection{Families}

Participation in faalavelave, provide a space of observation for understanding and learning. Building one's confidence to pursuit language learning opportunities.

Making a point to teach the next generation the practicalities of Samoan traditions and rituals, through appointing a time and space that is calm and comfortable. Although language may not be present learning one's genealogy, family history and culture can be beneficial in building a relationship between the generations. Examples can include prayer time with families, technology free evenings and following family mealtimes once a week.

Using Samoan numeracy and literacy games (examples could be Samoan card games) within the home to reinforce language skills.

Board games replacing English words, and numbers with Samoan terms for example scrabble, monopoly, charades, Pictionary.

Family Samoan story times and learning and practicing of Samoan prayers, hymns and songs.

\subsection{Concluding statement}

From the findings it is clear language, culture and identity are interconnected and when a shift of heritage language occurs this has a profound impact on one's wellbeing.

Samoan was not being spoken taught or supported within schools, and although Churches were still seen to be a hub of language and cultural maintenance / retention, the second generation are not attending or growing up in Samoan Churches. The need to find other 
ways the next generations can still learn from a Church model of maintaining Samoan is crucial.

Samoan is not being spoken within the homes due to the multifaceted levels of alofa - love and protection in response to policies and infrastructures rooted in colonialism. The acts of love committed by the second generation through seeking of different avenues to find or provide meaning and connection to language and culture for both themselves and their children highlighted the deep desire and yearning for reclamation of Samoan language. It is not due to lack of value or commitment from Samoan second generation that the language is slowly becoming endangered. There is no need for convincing that language needs to be maintained or efforts must be taken to ensure retention. Participants indicated a keen willingness to re-learn, reconnect and reclaim the Samoan language.

What needs to be looked at is how we can best teach our language back to our communities and future generations. The need for the language to be taught in a manner that is relatable, practical and safe knowing one's belonging is grounded within that locality despite insecurities of language ability or lack of cultural knowledge.

The yearning and love are what will drive the second generation to find ways of reclamation of language. What is required are the right support structures, linguistic policies, education support systems and commitments from government to best support these new developments

Samoan language provides new approaches and applications essential to new developments in the future. O le Filiga le Afa method is an example of this signifying that new areas of development is located in the nexus between Indigenous and Western knowledge. 


\section{Chapter 7 Final word}

A constant message that I received at the end of discussions was the relief to know they (the participants) were not alone in their experiences, challenges they faced and constant negotiation of the worlds in which they walk between. It was also noted that at the end of each discussion participants looked lighter and seemed calmer than when they had arrived. This highlighted that we need to be having more of these discussions and it is crucial they are had in safe spaces with no judgement or ridicule.

I want to re-iterate that I am not a competent speaker in either of my heritage languages. But I am trying to figure out a way to reclaim my mother tongues, this research was one way of learning. Upon taking this research journey I have learnt so much more than I could have ever imagined.

Do not let the narrative "if you are not a competent speaker in Samoan you are not a real Samoan" be what holds you back from reclaiming your language. 


\section{Glossary of terms and conceptual meanings}

Afa

Aga

Aganu'u

Aga I fanua

‘āiga

Agaifanua

Alofa

Ā'oga 'āmata

Ato

Autalavou

Faaaloalo

Fa'a Samoa

Faata'a

Faia

Fesoasoani

Feau
Coconut fibre /sennit

The way people do things to the land

- Custom

- Tu ma aga of the nu'u: not in this village/country/niche.

Locality. The aga of immediate locality or land

Family intergenerational and extended

Rule or law [pertaining to land and titles] t specifically applies to a family or a village and its origins in history and genealogy.

- Comes from the base word of alo. You face somebody - face to face relationship.

- staying present in thought in actions in prayer. Being present and having the presence of the other or others in your thought and in your actions.

- There's the physical, mental and spiritual side. These are the three sides to any one person. So being present physically, mentally and spiritual to the other one vice versa. That is what alofa is.

- If someone is present to you, you cannot avoid all the things the person goes through, all their joys, all their pains.

- Alofa is opening space for the presence of the other. Not located in individualistic things or nuclear family things. But talking about relationships, collectivises, and talking about extended family sense.

Samoan preschool.

Woven basket.

Youth group.

- To pay respect to.

- To be in the presence of people. Meaning to be in relationship with people.

To be like Samoa, or the actions of the culture of Samoa. Rolling of two or three matofi to create a thicker strand of sennit

Connections, your relationship. Your rights and entitlements are defined by your relationships.

Root word is soa translation is help - to be in partnership with. Soa presumes an equivalence to somebody. You are a partner to carry a load, physically, mentally spiritually. To partner in carrying the load. 
Filiga

Fulitua

Gagana

le toga

Lima lelei

LMS

Matai

Matofi

Mealofa

Meleke

Niu

Palatua

Pese

Pulu

Sasa le pulu

Si'i alofa

Siva

Talanoa

Tatau

Tautua

Taulotu

Tofa Sa'ili

Toli

Taomaga

Taulotu

Tuiga

Va / Vā Tapuia

Va tapuia
Braid, plait.

- Choice.

Turn your back on the relationship. No longer conscious of the person mentally, physically or spiritually.

- Root word is Aga - a set of behaviours, set of values, set of ethics, morals.

Fine mat.

- Language.

Careful enacting and embodying of the four spiritual relationships - to land, ancestors and genealogy, language and culture, connecting the present to earlier and to future generations.

London Missionary Society.

Titled head of Samoan extended family.

Separated coconut fibres.

Present /gift/charity.

Four leg stools.

Coconut.

Baton-like stick.

Song.

Coconut husk.

Pounding of the coconut husk.

Presentation of traditional gifts at funeral: lit. presenting out of love.

Dance.

Tala to tell, noa ordinary, nothing in particular or void. To chat

Traditional tattoo

Literally means that which meets your back. That which is carried on the back. Tau i le tua - it's the carriage of stuff. Tautua is to serve. The reliance on two people to carry the economic weight is not just on the two people in a family. In Samoa it would be a larger collective.

Recitation for verse.

Search for long view wisdom.

Choosing, to choose.

Soaking of the coconut husks in ocean /swamp.

Ceremonial head dress made of tufts of hair, bark cloth with upper structure of sticks and decorated with mirrors.

A relational space or boundaries which protect the relationship between the human Pacific relational person or human beings ad the environment, physical, sociopolitical and spiritual elements.

Sacred spaces/connections between people and things.

\section{Appendix}




\section{Symbol meanings in transcripts}

$[!]$ = Strong emphasis

[...] = Pause indicating thinking more deeply, choosing of words is occurring

$\left({ }^{*}\right)=$ Sentence is slightly edited

$<>=$ Large section of paragraph has been edited or cut out

$(+)=$ Not finishing off the sentence verbally - mutual understanding of what they are saying is being said

${ }^{*}=$ refer to appendix for translation

$\sim \sim$ purposeful voice change

${ }^{* * * *}=$ replacement of name

\section{Guiding questions}

I. What does being Samoan mean to you? What are the strengths that you draw from being Samoan or your language or culture?

Would you say you can speak Samoan? Yes - How did you learn to speak Samoan?

Lead on: Would you say then that it is important for your parents / family that you were taught Samoan also? Why do you think they saw this as important also?

No - In which context would you say you speak / hear the most Samoan?

Prompts: -Church, -Home with you or parents, University, -With friends, Family lunches, Samoan radio, Samoan movies or dramas etc

II. Is being able to speak Samoan something that is important to you?

Lead on: Why is it/has it been important to you to be able to speak Samoan? If culture is brought up: How does this make you more connected to your culture? Do you think you would have the same relationships you have today with family and friends if you were not able to speak Samoan?

III. You've spoken about why it is/is not important to you that you are able to speak Samoan/ how important the language is to you. Would you say that the way you see yourself as a young Samoan woman / man / person living in Aotearoa or overseas has been influenced by your ability to speak/not speak Samoan?

IV. When reflecting back, what would you say are some of the important factors that have helped you to retain your language? 
Lead on: Do you live close to your immediate and extended family? Do you get to see each other regularly? Do you find you speak more Samoan then English during these times of being with family or is it vice versa?

V. Did you attend an Ā'oga 'āmata (Samoan Preschool) as a child?

Do you remember what the transition was like from ECE to primary? Do you have any standout memories from Aoga Amata? Was Samoan ever offered as a subject throughout your primary and secondary schooling? If yes for offered at school- Did you take up the chance to learn/maintain Samoan at your school? Did you enjoy these classes were they well taught?

Lead on: No - Can you remember what language classes were taught at your school /college? Have you ever sought out Samoan language classes or a way to learn Samoan outside of your home?

VI. Is Church a big part of your life?

Either now or when you were growing up? Was /is it a Samoan speaking Church that you and your family attended? Do you spend a lot of time at your Church or with your Church community? Is Samoan the main form of communication while you are at Church or with your Church ‘āiga? (family)

VII. Do you get the chance to go back to Samoa every few years? Lead on: If so, do you find that returning back on a regular occasion helps you to retain your language. If not, do you find it makes it harder for you to keep your language alive? Would you want to make it a regular occurrence-returning to Samoa? Can you tell me a bit about what it is like being back in Samoa for you?

VIII. What's the hardest thing about not being able to speak Samoan? 


\section{Bibliography}

Adler, E., \& Clark, R (2011). An Invitation to Social Research: How It's Done. Fourth edition. Wadsworth Cenage Learning, California.

Anishnaabe Symbol-Based Reflection. International Journal of Qualitative Methods, 8(1). University of Alberta, Alberta, Canada.

Amituanai -Toloa, M. (2010). To each a language: Addressing the challenges of language and cultural loss for Samoans. AlterNative: An indigenous journal of Indigenous Peoples, 6 (2), 70 - 85.

Anae, M (1998). Fofoa-i-vao-ese: The identity journeys of NZ-born Samoans.

(Doctoral thesis). University of Auckland, New Zealand. Retrieved from https://researchspace.auckland.ac.nz/docs/uoa-docs/rights.html

Anishnaabe Symbol-Based Reflection. International Journal of Qualitative Methods, 8(1). University of Alberta, Alberta, Canada.

Baker, W. (2015). Thinking allowed: Research into practice: Cultural and intercultural awareness. Language Teaching, 48.1, 130 - 141.Cambridge University Press.

Barnes, H., Samu, LJ., Asiasiga, L., \& McCreanor. (2019). We are not privileged enough to have that foundation of language: Pasifika young adults share their deep concerns about the decline of their ancestral/heritage languages in Aotearoa New Zealand. AlterNative 15 (2) 131 -139. Sage Publishing, California.

Bedford, R., \& Didham, R., (2001). Who are the 'Pacific peoples'? Ethnic identification and the New Zealand census. In Macpherson, Spoonley \& Anae (Eds), Tangata o te Moana Nui: The evolving identities of Pacific peoples in Aotearoa New Zealand (pp. 21-43) Dunmore Press, Palmerston North, New Zealand.

Bell, Derrick (1992, 1995). The Handbook of Social Research Ethics. (Eds.) Mertens \& Ginsberg. Sage Publishing Inc, Thousand Oaks, California.

Bell, Derrick. (2005). The Derrick Bell Reader. (Eds.) Delgado \& Stephancic. New York University Press.

Benton, R. (1995). Towards a languages policy for New Zealand education. New Zealand Annual Review of Education, 4, 11 -173.

Boyatziz, R. (1998). Transformative qualitative information:Thematic analysis and code development. Sage Publishing, Thousand Oaks, California.

Braun, V \& Clarke, V. (2006) Using thematic analysis in psychology. Qualitative research in psychology, 3 (2), $77-101$.

Buck, Sir P / Hiroa, T.R. (1930). Samoan material culture. Bernice P. Bishop Museum Bulletin 15, 230 - 261. Honolulu, Hawaii. 
Chodkiewicz, A. (2011). Exploring and supporting home language maintenance in informal playgroups working with Pacific communities. Auckland University of Technology Heritage Language Journal 8 (2).

"Community Po Talanoa by Avaniu Pasifika" 2019. Retrieved from https://www.eventfinda.co.nz/2019/community-po-talanoa-by-avaniu-pasifika/bay-ofplenty

Congregational Christian Church of Samoa (2019). Brief History. Retrieved from http://www.cccs.org.ws/index.php/about-us

Clandinin, J. \& Connelly, M. (1999). Narrative Inquiry: Experience and Story in Qualitative Research. John Wiley \& Sons, Inc.

Coyner, A.L (2005). Sound like you speak good Samoan: Performance, identity and language use at a Samoan Church (Master's Thesis). California State University, Long Beach, ProQuest Dissertations Publishing, 1429306.

Dickie, J and McDonald, G. (2011). Literacy in Church and family sites through the eyes of Samoan children in New Zealand. Wiley Online Library: Literacy, 45, 25-31. Retrieved from https://doi.org/10.1111/j.1741-4369.2011.00574.x

Ete, F. (1993). The role of the Church and government in promoting early childhood education in Aotearoa. Paper presented at the New Zealand Council for Educational Research Invitational Seminar. Wellington.

Field, M. (1984). MAU Samoa's struggle against New Zealand oppression. A.H \& A.W REED LTD.

Fouvaa, M. (2011). O le a le Matafaioi o le Fono a le Aiga ma le Fono a le Lotu i le Faatumau ai o le Gagana Samoa i Niu Sila? What is the Role of Family Fono and Church Fono in the Maintenance of Samoan Language in New Zealand? (Doctorate thesis) University of Auckland. Retrieved from https://researchspace.auckland.ac.nz/docs/uoa-docs/rights.htm

García, M. (2003). 2. Recent Research on Language Maintenance. Annual Review of Applied Linguistics, 23, 22-43. Retrieved from doi:10.1017/S0267190503000175

Given, L. M. (2008). The SAGE encyclopedia of qualitative research methods (Vols. 1-0). Thousand Oaks, CA: SAGE Publications, Inc. doi: 10.4135/9781412963909

Golombek, P. (1998). A Study of Language Teachers' Personal Practical Knowledge. TESOL Quarterly, 32 (3), 447-64.

Halapua, S. (2008). Talanoa process: The case of Fiji. (Doctorate thesis). East-West Centre, Honolulu, Hawai'i.

Holmes, J, 'Aiopolo, A,. Roberts, M and Verivaki, M (1993). Language Maintenance and Shift in Three New Zealand Speech Communities. Applied Linguistics, (14), 1-24. Retrieved from https://doi.org/10.1093/applin/14.1.1 
Hunkin, G. (2012). To let die: The state of the Samoan language in New Zealand. AlterNative an international journal of indigenous peoples. 8 (2) 203-214. Sage Publishing, California.

Kanuha, V. K. (2000). "Being" native versus "going native": Conducting social work research as an insider. Social Work, 45(5), 439-447

Kearney, J., Fletcher, M. and Dobrenov-Major, M. (2014). Non-aligned worlds of home and school: A case study of second-generation Samoan children. Retrieved from https://doi.org/10.5172/jfs.2011.17.2.146

King, J., and Cunningham, U. (2017). Tamariki and fanau: Child speakers of Māori and Samoan in Aotearoa. Linguistic Society of New Zealand, Auckland. Te Reo Journal, 60.

Kramer, A. (1995). The Samoa Islands: An Outline of a Monograph with Particular Consideration of German Samoa, volume 2: Material Culture. University of Hawai'i Press Honolulu Polynesian Press.

Lavallee, F. L. (2009). Practical Application of an Indigenous Research Framework and Two Qualitative Indigenous Research Methods: Sharing Circles and

Lesa, F. (2009). The impact of Samoan Christian Churches on Samoan language competency and cultural identity. (Doctorate thesis). University of Hawaii, Manoa. Retrieved from http://www.proquest.com/en-US/products/dissertations/individuals.shtml

Lochner, L. (2008). Intergenerational Transmission, New Palgrave Dictionary of Economics, (2)

Masina, P. (1996). The emergence of the Samoan language in New Zealand education. (Master's thesis). Victoria University. Wellington.

Mejia, G. (2016) Language usage and culture maintenance: a study of Spanish speaking immigrant mothers in Australia, Journal of Multilingual and Multicultural Development, 37:1, 23-39, DOI:10.1080/01434632.2015.1029931

Miller, G. (1966) In Samoan Dictionary. Pasifika Press, Auckland, New Zealand

Ngaha, A. (2005). Language and identity in the Māori community: Without the reo, who am I. University of Auckland. Retrieved from http://www.nzlingsoc.org/documents/ngaha/pdf.

Nieto, S. (2002). Language, culture, and teaching: Critical perspectives for a new century. 5, (4). Mahwah, NJ: Lawrence Erlbaum Associates. Routledge, New York.

Ostler, R. (August/September,1999). Disappearing Languages. The Futurist 33,7, p.16

Percival, S. (2002). O le aso ma le filiga, o le aso ma le mata'igatila: exploring the use of natural fibres in Samoa. [Video file]. Paradigm Documentaries. Retrieved from Alexander Street database. 
Radio New Zealand (2019). Seven weeks journey to Polyfest. Retrieved from https://www.rnz.co.nz/national/programmes/afternoons/audio/2018686526/journeyto-polyfest

Field, M., \& Salesa, D. (Radio New Zealand). (2017, September, 4). Epidemic the story of Robert Logan [Audio Podcast] Retrieved from https://www.rnz.co.nz/programmes/black-sheep/story/201856326/epidemic-thestory-of-robert-logan

Samu, L. - J.V, Moewaka Barnes, H., Asiasiga, L., \& McCreanor, T. (2019)."We are not privileged enough to have that foundation of language": Pasifika young adults share their deep concerns about the decline of their ancestral/heritage languages in Aotearoa New Zealand. AlterNative: An International Journal of Indigenous Peoples, 15(2), 131-139. https://doi.org/10.1177/1177180119835228

Sauvao, F. (2002). Transition of Samoan children from Ā'oga 'āmata to primary school: Case study of the Wellington Region. Paper presented at the Pacific Bilingual Conference, Auckland. Retrieved from https://eric.ed.gov/?id=ED47345

Sauvao-Va'auli, I. (2017). Samoan leadership for New Zealand-born Samoan through Aganu'u journey of discovery. Auckland University of Technology. Retrieved from https://openrepository.aut.ac.nz/handle/10292/11705

Schwandt, T. (1997). The landscape of values in evaluation: Chartered terrain and unexplored territory. In: Fournier, D., Rog, D.J., eds. Progress and future directions in evaluation: Perspectives on theory practice, and methods. New directions for evaluation 76. San Francisco: Jossey-Bass, pp. $25-40$

Seals, C. (2017). Pasifika heritage language education in New Zealand. Routledge handbook of heritage language education. Taylor and Francis. Retrieved from http://ebookcentral.proquest.com/lib/vuw/detail.action?doclD=4816651.

Shilling, N. (2013). Sociolinguistic Fieldwork. Key topics in sociolinguistics. Cambridge University Press, New York.

So'o, I. Personal communications, August 21, 2019.

Spoonley, P., and Bedford, R. (2012) Welcome to Our World? Immigration and the Reshaping of New Zealand. Auckland: Dunmore Publishing

Starks, D. (2008). The Effects of Self-confidence in Bilingual Abilities on language Use: Perspectives on Pasifika Language Use in South Auckland. Journal of Multilingual and Multicultural Development. 26 (6). Retrieved fromhttps://doi.org/10.1080/01434630508668424

Statistics New Zealand. (2014a). 2013 Census QuickStats about culture and identity. Retrieved from http://www.stats.govt. nz/Census/2013-census/profile-and-summaryreports/quickstats-culture-identity/pacific-peoples.aspx

Statistics New Zealand (2014b). 2013 Census ethnic group profiles: Cook Islands Maori. Retrieved from http://www.stats.govt.nz/Census/2013-census/profile-and-summaryreports/ethnic-profiles.aspx?request_value=24709\&tabname=Languagesspoken 
Statistics New Zealand. (2014c). 2013 Census ethnic group profiles: Fijian. Retrieved from http://www.stats.govt.nz/Census/2013-census/profile-and-summary-reports/ethnicprofiles.aspx ?request_value $=24714 \&$ tabname $=$ Languagesspoken

Statistics New Zealand. (2014d). 2013 Census ethnic group profiles: Niuean. Retrieved from http://www.stats.govt.nz/Census/2013-census/profile-and-summaryreports/ethnic-profiles.aspx?request_value=24712\&tabme=Languagesspoken

Statistics New Zealand: Data Info Plus. (n.d.) Second Generation New Zealander. Retrieved from http://datainfoplus.stats.govt.nz/item/nz.govt.stats/06d75f93-1a364a7e-84fd-a84ebd7966cf/1/

Tamasese, T.K. Personal communications, August 16, 2019

Tamasese, T.K. Personal communications, August 23, 2019

Tamasese, T.K. Personal communications, August 30, 2019

Tamasese, T.K. Personal communications, November 22, 2019

Tamasese, T. K., Waldergrave, C., \& King, P. (2000). A review of lottery responsiveness to Pacific community groups: A cultural audit of the lottery grants board. The Family Centre Social Policy Research Unit, Lower Hutt, Wellington.

Tamasese, T.K., Parsons, T.L., Sullivan, G., \& Waldgrave, C. (2010). A qualitative study into Pacific perspectives on cultural obligations and volunteering. Pacific Section, The Family Centre Social Policy Research Unit, Lower Hutt, Wellington.

Tamasese, T.K., Parsons, T.L., \& Waldegrave, C. (2014). Pacific perspectives on Ageing in New Zealand Pacific-focused qualitative research prepared for the New Zealand Longitudinal Study of Ageing (NZLSA). The Family Centre, Lower Hutt, Wellington.

Tamasese, P. T. K., \& Parsons, T.L. (2019). Tofa Sa'ili I le Mataupu o Le Soifua Manuia, Soifua Manuia, Soifua Tamaoaiga, Soifua Maloloina ma Iona Tafagaina Pacific Conceptions of Wellbeing, Spirituality, Resilience and the Measurement of Pacific Intergenerational Wellbeing. The Family Centre, Lower Hutt, Wellington.

Tamasese, Tui Atua Tupua Efi. (2000). Gapia: FaaSamoa speaks to my heart and my soul. Paper presented: Pasifika Medical Association 3rd Health Conference, Auckland, New Zealand.

Tamasese, Tui Atua Tupua Ta'isi Efi. (2003). In Search of Meaning, Nuance and Metaphor in Social Policy. Social Policy Issue of New Zealand, 20. New Zealand. Retrieved from https://www.msd.govt.nz/about-msd-and-our-work/publicationsresources/journals-and-magazines/social-policy-journal/spj20/nuance-and-metaphorin-social-policy-20-pages49-63.html

Tamasese, Tui Atua Tupua Ta'isi Efi. (2005). In Search of Harmony: Peace in the Samoan Indigenous Religion. Paper presented at the Pacific regional international colloquium on Indigenous cultural and religious concepts of peace and good governance.

Tafamamao, Leauvaa, Samoa. 
Tamasese, Tui Atua Tupua Ta'isi Efi and the Samoan Indigenous Reference (2018). Su'esu'e Manongi In Search of Fragrance. Huia Publishing, Wellington, New Zealand.

Tiatia, J., \& Deverell, G. (1998). Caught between cultures: a New Zealand-born Pacific Island perspective. Auckland [N.Z: Christian Research Association.

Tuāfuti, V. (2016). Pululima Faifai Pea: Establishment of Sāmoan Immersion Early Childhood Education Centres \& Bilingual Units in Primary and Intermediate Schools (Doctorate thesis). University of Waikato, Hamilton, New Zealand. Retrieved from https://hdl.handle.net/10289/10683

Tualaulelei, E. (2008). Indicators of language shift from a public face of a Samoan speech community. New Zealand Studies in Applied Linguistics, 14 (1).

Tunufa'i, L. (2016) Pacific research: Rethinking the Talanoa 'methodology'. New Zealand Sociology, 31 (7).

United Nations Climate Change (2019). 2019 Talanoa Dialogue Platform. Retrieved from https://unfccc.int/process-and-meetings/the-paris-agreement/the-parisagreement/2018-talanoa-dialogue-platform

Violeti, T. (2006). Talanoa research methodology: A developing position on Pacific research. Waikato Journal of Education, 12. University of Waikato.

Waite, J. (1992a). Aoteareo Speaking for Ourselves: A Discussion on the Development of a New Zealand Languages Policy, Part A: The Overview. Victoria University of Wellington, Wellington.

Waite, J. (1992b). Aoteareo Speaking for Ourselves: A Discussion on the Development of a New Zealand Languages Policy, Part B: The Issues. Victoria University of Wellington, Wellington.

Wilson, S. (2010). Le tofi nei valetuulima Perceptions of Samoan students, teachers and parents on the place of Samoan language in New Zealand. (Master's thesis). Victoria University, Wellington. Retrieved from http://researcharchive.vuw.ac.nz/bitstream/handle/10063/1452/thesis.pdf?sequence= 1

Wilson, S. (2017). A malu i fale le gagana, a e malu fo'i i fafo. The use and value of the Samoan language in Samoan families in New Zealand. (Doctorate thesis). Auckland University of Technology. Retrieved from https://core.ac.uk/download/pdf/132419334.pdf 


\section{Qualitative study in Samoan language maintenance and the relationship between Language shift and wellbeing}

\section{INFORMATION SHEET FOR PARTICIPANTS}

You are invited to take part in this research. Please read this information before deciding whether or not to take part. If you decide to participate, Faafetai tele lava. If you decide not to participate, faafetai for considering this request.

\section{Who am I?}

My name is Leitumalo and I am a Masters student in Applied Linguistics at Victoria University of Wellington. This research project is work towards my thesis.

What is the aim of the project?

The aim of this project to investigate the maintenance of Samoan language in Aotearoa and look at whether there is a relationship between one's wellbeing and Samoan language shift.

What will happen to the information you give?

This research is confidential. This means that the researcher named below will be aware of your identity, but your identity will not be revealed in any reports, presentations, or public documentation. However, you should be aware that in small projects your identity might be obvious to others in your community.

Only my supervisor and I will read the notes or transcript of the interview. The interview transcripts, summaries and any recordings will be kept securely and destroyed indefinitely.

\section{What will the project produce?}

The information from my research will be used for my Masters thesis; A qualitative study looking into Samoan language maintenance and the relationship between Wellbeing and Samoan language shift. The findings from this study may also be published or presented at conferences in the near future.

\section{If you accept this invitation, what are your rights as a research participant?}

You do not have to accept this invitation if you don't want to. If you do decide to participate, you have the right to:

- $\quad$ choose not to answer any question; 
- $\quad$ ask for the recorder to be turned off at any time during the interview;

- $\quad$ withdraw from the study before 1/3/2019;

- $\quad$ ask any questions about the study at any time;

- $\quad$ receive a copy of your interview recording;

- $\quad$ receive a copy of your interview transcript;

- $\quad$ read over and comment on a written summary of your interview

- $\quad$ be able to read any reports of this research by emailing the researcher to request a copy.

If you have any questions, either now or in the future, please feel free to contact me:

\section{Human Ethics Committee information}

If you have any concerns about the ethical conduct of the research, you may contact the Victoria University HEC Convenor: Dr Judith Loveridge. Email hec@vuw.ac.nz or telephone +64-4-463 6028. 


\section{Qualitative study in Samoan language maintenance and the relationship between Language shift and wellbeing CONSENT TO INTERVIEW}

This consent form will be held for indefinitely.

Researcher: Leitumalo Parsons, School of Linguistics and Applied Language Studies, Victoria University of Wellington.

- I have read the Information Sheet and the project has been explained to me. My questions have been answered to my satisfaction. I understand that I can ask further questions at any time.

- I agree to take part in an audio recorded interview.

I understand that:

- I may withdraw from this study at any point before $1 / 3 / 2019$, and any information that I have provided will be returned to me or destroyed.

- The identifiable information I have provided will be destroyed on indefinitely.

- $\quad$ Any information I provide will be kept confidential to the researcher and the supervisor.

- I understand that the results will be used for a Masters thesis.

- $\quad$ My name will not be used in reports, nor will any information that would identify me.

- I would like a copy of the recording of my interview:

Yes $\square \quad$ No

- I would like a copy of the transcript of my interview:

Yes $\square \quad$ No

- I would like a summary of my interview:

Yes $\square \quad$ No

- I would like to receive a copy of the final report and have added my email $\quad$ Yes $\square$ No address below.

Signature of participant:

Name of participant: 
Date:

Contact details: 


\section{Information sheet: Meanings}

\section{What is Talanoa:}

As Samoan and Pasifika people Talanoa is something that is not only natural to us but a way in which we share our ideas and discuss important matters. Vaioleti, (2006) once explained Talanoa; Noa is to create the space and conditions, while Tala is the holistic intermingling of researchers and participants emotions, knowing and experiences. Talanoa can also be a time of gathering, sharing of food and talking together. My method of data collection is Talanoa, which is why I will be calling our sessions "Talanoa catch ups" or "Talanoa sessions" and not Interviews.

\section{What is language shift?}

"Language shift" means the process, or the event, in which a population changes from using one language to another. As such, recognition of it depends on being able to see the prior and subsequent languages as distinct; therefore, the term excludes language change which can be seen as evolution, the transition from older to newer forms of the same language. (Oxforddictionary.com), In this case, the language shift is the use of Samoan slowly declining and not being used or maintained amongst Samoans living in Aotearoa and instead being replaced by English.

\section{What is Wellbeing?}

There are many different definitions of wellbeing. However, in this study I am particularly interested in what Wellbeing means to you? This may include Spiritual Wellbeing, Holistic Wellbeing, Mental Wellbeing, and/or Physical Wellbeing. This is similar to how health is not just about physical health as once described by a participant in a previous case study "Health is not about your physical health but about the maintenance of harmony in relationships among family and deceased" (Parsons, 1985, p. 90; quoted in Leslie, 1999, pp. 152-3). There is no definitive answer for what Wellbeing is, which is why it is important to hear your ideas on what Wellbeing means and feels for you. 
Please note that withdrawal of an individual's contribution to a focus group is only possible up until the commencement of the group discussion. Although the participants can choose to leave the focus group discussion at any time, it will be impossible to withdraw what has been said by them up to the point of their withdrawal as it will be incorporated into of the general discussion with other participants. This feature should be explained in the Information sheet provided to your participants.

\section{Focus group rules}

A document with proposed focus group rules should be uploaded to your Human Ethics application. Below are some examples of suggested rules to be included.

- The information shared in this meeting is confidential. You should not discuss the opinions and comments made by other focus group participants with anybody outside this room. We would like you and others to feel comfortable when sharing information.

- You do not need to agree with others, but you should listen respectfully as others share their views.

- We would like to hear a wide range of opinions: please speak up on whether you agree or disagree.

- There are no right or wrong answers, every person's experiences and opinions are important.

- The meeting is audio recorded, therefore, please one person speak at a time.

- Please turn off your phones. 
Qualitative study in Samoan language maintenance and the relationship between Language shift and wellbeing

\section{INFORMATION SHEET FOR PARTICIPANTS [for Focus Groups]}

You are invited to take part in this research. Please read this information before deciding whether or not to take part. If you decide to participate, thank you. If you decide not to participate, thank you for considering this request.

\section{Who am I?}

My name is Leitumalo and I am a Masters student in Applied Linguistics at Victoria University of Wellington. This research project is work towards my thesis.

\section{What is the aim of the project?}

The aim of this project to investigate the maintenance of Samoan language in Aotearoa and look at whether there is a relationship between one's wellbeing and Samoan language shift.

This research has been approved by the Victoria University of Wellington Human Ethics Committee 0000026955

\section{How can you help?}

You have been invited to participate because your thoughts, knowledge and voice are of high value. You are Samoan, born and raised in Aotearoa, and as second/ third generation Samoans living in Aotearoa it is important to understand the journey of Samoan language maintenance or shift for Samoans living in Aotearoa. Your knowledge and journey can help us to understand better what we can do to try and ensure the Samoan language is better maintained in Aotearoa. Your own understanding and meanings for wellbeing as Samoan people can contribute to our own Pasifika definitions of Wellbeing that is not dictated by a Western narrative.

If you agree to take part in our Talanoa session, will take place at a location that is agreed on by both participant and researcher. We will Talanoa about being Samoan and growing up in Aotearoa and what the Samoan language means to you and how you choose to uphold the Samoan language. We will also discuss what your own perceptions are around wellbeing and what wellbeing means for you as a Samoan growing up in Aotearoa. This Talanoa session can take up to two hours and go on for longer if need be. The length of time is dictated by you the participant. I will audio record the interview with your permission and transcribe it later. 


\section{What will happen to the information you give?}

This research is confidential. This means that the researcher named below will be aware of your identity, but your identity will not be revealed in any reports, presentations, or public documentation. It is important to note also, that However, you should be aware that in small projects your identity might be obvious to others in your community.

Only my supervisors I will read the notes or transcript of the focus group. The focus group transcripts, summaries and any recordings will be kept securely and destroyed indefinitely.

\section{What will the project produce?}

The information from my research will be used in my Masters thesis; A qualitative study looking into Samoan language maintenance and the relationship between Wellbeing and Samoan language shift.

\section{If you accept this invitation, what are your rights as a research participant?}

You do not have to accept this invitation if you don't want to. If you do decide to participate, you have the right to:

- $\quad$ choose not to answer any question;

- $\quad$ ask for the recorder to be turned off at any time during the focus group;

- $\quad$ withdraw from the focus group while it is taking part however it will not be possible to withdraw the information you have provided up to that point;

- $\quad$ ask any questions about the study at any time;

- $\quad$ read over and comment on a written summary of the focus group

- be able to read any reports of this research by emailing the researcher to request a copy.

\section{Human Ethics Committee information}

If you have any concerns about the ethical conduct of the research you may contact the Victoria University HEC Convenor: Dr Judith Loveridge. Email hec@vuw.ac.nz or telephone +64-4-463 6028. 


\section{Qualitative study in Samoan language maintenance and the relationship between Language shift and wellbeing}

\section{CONSENT TO PARTICIPATE IN FOCUS GROUP}

This consent form will be held indefinitely.

Researcher: Leitumalo Parsons, School of Linguistics and Applied Language Studies, Victoria University of Wellington.

- I have read the Information Sheet and the project has been explained to me. My questions have been answered to my satisfaction. I understand that I can ask further questions at any time.

- I agree to take part in an audio recorded focus group.

I understand that:

- I acknowledge that I am agreeing to keep the information shared during the focus group confidential. I am aware that after the focus group, I must not communicate to anyone, including family members and close friends, any details about the focus group.

- I can withdraw from the focus group while it is in progress however it will not be possible to withdraw the information I have provided up to that point as it will be part of a discussion with other participants

- $\quad$ The identifiable information I have provided will be destroyed indefinitely.

- $\quad$ Any information I provide will be kept confidential to the researcher and the supervisor.

- I understand that the results will be used for a Masters thesis.

- My name will not be used in reports, nor will any information that would identify me.

- I would like a summary of the focus group: $\quad$ Yes $\square$ No

- $\quad$ I would like to receive a copy of the final report and have added my email Yes $\square \quad$ No address below.

Signature of participant: 
Name of participant:

Date:

Contact details: 
